\title{
The effect of pegylation and targeting moieties on the ultrasound-mediated drug release from
}

\section{liposomes}

\author{
Nahid S. Awad ${ }^{a}$, Vinod Paul a, Mohamad S. Mahmoud ${ }^{a}$, Nour M. AlSawaftah ${ }^{b}$, Paul S. Kawak ${ }^{b}$, \\ Mohammad H. Al Sayah c,d, Ghaleb A. Husseini*,a,d \\ ${ }^{a}$ Department of Chemical Engineering, American University of Sharjah, Sharjah, UAE \\ ${ }^{b}$ Department of Biomedical Engineering, American University of Sharjah, Sharjah, UAE \\ cDepartment of Biology, Chemistry and Environmental Sciences, American University of \\ Sharjah, Sharjah. UAE \\ ${ }^{d}$ Biosciences \& Bioengineering Research Institute, American University of Sharjah, PO. Box \\ 26666, Sharjah. UAE \\ E-mail: ghusseini@aus.edu (Corresponding author)
}

This is a manuscript copy of:

Awad, N., Paul, V., Mahmoud, M., Al Sawaftah, N., Kawak, P., Al Sayah, M., \& Husseini, G. (2019). Effect of pegylation and targeting moieties on the ultrasoundmediated drug release from liposomes. ACS Biomaterials Science \& Engineering. doi:10.1021/acsbiomaterials.8b01301 https://doi.org/10.1021/acsbiomaterials.8b01301 


\title{
The effect of pegylation and targeting moieties on the ultrasound-mediated drug release from liposomes
}

\begin{abstract}
:
The use of targeted liposomes encapsulating chemotherapy drugs enhances the specific targeting of cancer cells, thus, reducing the side effects of these agents and providing a more patient-friendly treatment. Targeted pegylated (stealth) liposomes have the ability to safely deliver their loaded drugs to the cancer cells by targeting specific receptors overly expressed on the surface of these cells. Applying ultrasound as an external stimulus will safely trigger drug release from these liposomes in a controlled manner. In this study, we investigated the release kinetics of the model drug "calcein" from targeted liposomes sonicated with low-frequency ultrasound $(20-\mathrm{kHz})$. Our results showed that pegylated liposomes were more sonosensitive compared to non-pegylated liposomes. A comparison of the effect of three targeting moieties conjugated to the surface of pegylated liposomes, namely human serum albumin (HSA), transferrin (Tf) and arginylglycylaspartic acid (RGD), on calcein release kinetics was conducted. The fluorescence results showed that HSA-PEG and Tf-PEG liposomes were more sonosensitive (showing higher calcein release following the exposure to pulsed LFUS) compared to the control pegylated liposomes. Thus, adding more acoustic benefits to their targeting efficacy.
\end{abstract}

Keywords: targeted liposomes, release kinetics, ultrasound. 


\section{Introduction}

Chemotherapeutic agents are usually injected into the bloodstream and circulate throughout the body hindering tumor growth by destroying the cancer cells. Unfortunately, chemotherapy drugs can also affect fast-growing healthy cells including, hair and skin, limiting the drug dosage that can be administrated ${ }^{1}$. Nanocarriers encapsulating anti-neoplastic chemicals are a promising approach to limit the side effects of conventional chemotherapy while ensuring specific and effective drug delivery to the tumor site. These nanocarriers are designed to be biocompatible and biodegradable. In addition, nanocarriers are capable of accumulating at the tumor site by penetrating through the leaky blood vessels formed as a result of the aberrant angiogenesis in tumors $^{2}$. Several nanocarriers have been successfully developed, including liposomes, polymeric micelles, dendrimers, solid lipid nanoparticle, nanoshells, quantum dots, and others ${ }^{3}$. The surfaces of these nanocarriers can be further modified to enhance their efficiency, e.g. by the conjugation of polyethylene glycol (PEG) to provide stability, as well as, significantly prolonging their circulation time. Also, the surfaces of these nanocarriers can be crafted with selected molecules for the specific targeting of the cancer cells depending on the particular characteristics of these cells. Following their accumulation at the tumor site, it is important to apply stimuli or smart triggering mechanisms that are strong enough to trigger the release of the encapsulated drugs in a safe and controlled manner (spatially and temporally). Nanocarriers can be designed to be responsive to a type of internal (temperature, $\mathrm{pH}$ and enzymes) or external stimuli (ultrasound, light and magnetic field).

Liposomes are nanoparticles comprised of a phospholipid bilayer forming a spherical shape surrounding an aqueous compartment. When amphipathic phospholipids are exposed to water, they tend to reassemble themselves into tiny spheroidal structures that are either bi-layered (e.g. 
liposomes) or mono-layered (e.g. micelles) ${ }^{4}$. The unique structure of the liposomes allows the encapsulation of both the hydrophilic drugs, in the core, and the hydrophobic drugs, between the phospholipids bilayer ${ }^{5}$. Liposomes coated with polymers, such as polyethylene glycol (PEG), are known as "stealth liposomes". PEG is non-ionic, non-toxic and possesses high solubility in both aqueous and organic media ${ }^{6-8}$. Without being stealthy, the conventional liposome will be exposed to physical interaction with specific circulating proteins in the bloodstream, a process known as opsonization, leading to its clearance from the bloodstream 9 .

Liposomes can target tumors either passively or actively. Passive targeting depends on the small size of these liposomes which allows them to permeate into the tumor benefitting from the fast forming blood vessels surrounding the tumor tissues (angiogenesis). Angiogenesis leads to tumor development of secondary malignant growths. This is achieved through enhancing the entry of tumor cells into the circulation by providing an increased density of immature, highly permeable blood vessels that have fewer intercellular junctional complexes than normal mature vessels ${ }^{10-11}$. The endothelial cells of the tumor vessels lack the smooth muscle layer leading to non-aligned endothelial vascular lining structures ${ }^{12}$. These leaky vessels will allow nanoparticles such as liposomes, to pass through and accumulate at the tumor site. Liposomes accumulate inside the tumor tissues due to the lack of a functional drainage system in these tissues and therefore, these liposomes are not efficiently cleared and thus retained for prolonged period of time. This is known as the "enhanced permeability and retention" (EPR) effect ${ }^{13}$. "Active targeting", on the other hand, depends on the presence of specific receptors on the surface of the cell membrane of cancer cells allowing for receptor moiety interaction. The surfaces of the targeted liposomes are crafted with targeting moieties capable of binding to these receptors, thus ensuring the specific delivery of the chemotherapeutic drugs to the tumor and minimizing the agent's side effects ${ }^{14}$. 
While targeted liposomes are efficient in delivering the anti-neoplastic agent to the tumor site, a trigging mechanism is needed to initiate the release of the encapsulated drug in an efficient, controlled and speedy manner. A number of internal and external triggering mechanisms have been investigated including $\mathrm{pH}$, temperature, enzymes and UV-light stimuli ${ }^{15-18}$. US is also a promising effective modality for triggering the release of encapsulated drugs; it is non-invasive and used widely in the medical field for diagnostic, imaging and therapeutic purposes. US consists of mechanical waves which propagate through various media transmitting as alternating series of compressions (zones of high pressure) and refraction (zones of low pressure) ${ }^{19}$.

Triggered release of the drug from a variety of nanocarriers can be achieved utilizing US, which produces thermal and/or mechanical effects by either cavitation phenomena, radiation forces, or both ${ }^{20-21}$. Ultrasound waves can produce two types of effects, thermal and the non-thermal (mechanical), depending on the frequency, intensity and length of exposure. The thermal effects are generally generated by the high-intensity focused US (HIFU) in the continuous mode. Acoustic cavitation is an important mechanical component of the ultrasound ${ }^{19}$. The generated ultrasound waves create areas of "compression" and "rarefaction" producing what is known as "cavitation", whereby bubbles oscillate and may collapse in an acoustic field. Acoustic cavitation is divided into "stable cavitation" and "inertial/collapsed cavitation" (Figure 1), with the latter being implicated in the initiation of drug release from liposomes ${ }^{22}$. 


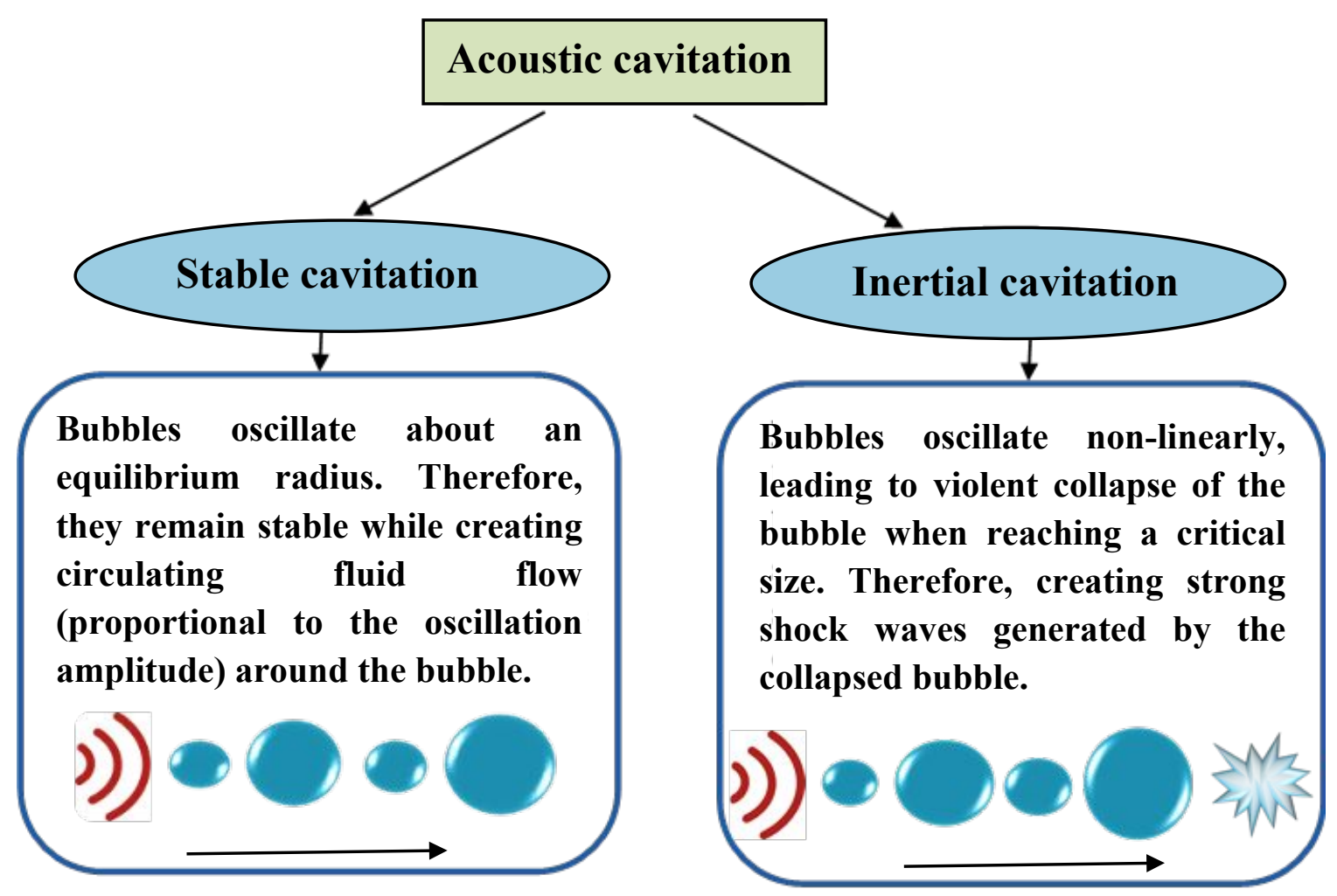

Figure 1. The mechanical effects of the ultrasound are generated by the stable cavitation and the inertial cavitation.

A number of studies have investigated the role of cavitation effects produced by non-focused lowfrequency $(20-\mathrm{kHz}$ to $90-\mathrm{kHz})$ ultrasound in drug release from liposomes and micelles. Husseini et al. ${ }^{23}$ showed that ultrasound waves at $70-\mathrm{kHz}$ applied at different intensities caused cavitation effects resulting in perturbing the structure of the micelles, which lead eventually to drug release. Low-frequency ultrasound $(20-\mathrm{kHz})$ applied to liposomes ${ }^{24}$ and polysomes ${ }^{25}$, showed that cavitation events led to the increase in drug release by inducing transient pore formation or porelike defects on the membrane through which the drug is rapidly released. These defects are most likely due to the mechanical effects of cavitation induced by the low-frequency ultrasound 
occurring next to the liposomes. These pore-like defects in the membrane reseal once the ultrasound waves cease ${ }^{24}$.

An in vitro study investigating ultrasound triggered release from liposomes showed that $20-\mathrm{kHz}$ ultrasound released significantly more of the encapsulated drug compared to high-frequency ultrasound $(1-\mathrm{MHz} \text { and } 3-\mathrm{MHz})^{26-27}$. The enhanced release is attributed to intensities needed to induce transient cavitation at low frequencies ${ }^{28}$. The presence of air bubbles is essential for the acoustic cavitation to take place. Hansen et al. ${ }^{29}$ reported that degassing and reducing the air bubbles in collagen gels resulted in reducing the cavitation effect which in turn, significantly reduced Doxorubicin release from the liposomes.

Once injected into the bloodstream, liposomes accumulate at the tumor site benefiting from the EPR effect associated with the tumor's leaky vasculature. However, to unlock the full potentials of these nanocarriers, it is essential that drugs encapsulated inside the liposomes are released in an efficient and controlled manner. A number of in vivo studies investigated the effect of ultrasound waves in triggering drug release from the liposomes. It is important to note here that ultrasound needs to be focused to reach the targeted deep tissues in the body. Pitt et al. ${ }^{30}$ have shown that combining low-frequency ultrasound $(20-\mathrm{kHz})$ with stealth liposomes encapsulating Doxorubicin (Dox-liposomes) led to significant tumor regression within 4 weeks compared to non-sonicated tumors in rats. High-intensity focused ultrasound (HIFU) combined with Dox-liposomes showed promising results in treating brain tumors in mice compared to Dox-liposomes only ${ }^{31}$. In vivo studies of low-frequency ultrasound (LFUS) combined with liposomes encapsulating fluoresceinisothiocyanate (FITC)-dextran ${ }^{32}$ and Dox-liposomes ${ }^{33}$ showed that liposomes exposure to LFUS significantly increased the release of their encapsulated drugs. More recent studies by Santos et al. ${ }^{34}$ and Um et al. ${ }^{35}$ showed that drug release from thermosensitive liposomes was enhanced by 
high- and low-frequency ultrasound, respectively. In addition, low-intensity focused ultrasound (LIFU) was found to enhance drug release from liposomes. Chen et al. ${ }^{36-37}$ showed that ultrasound can deliver water-soluble genes into cardiac muscles and pancreatic islet cells using liposomes.

A study ${ }^{38}$ on the effect of pegylation on liposomal stability has shown that the fluidity of the lipid bilayer increased in the presence of short-chain PEG e.g. PEG-1000. However, PEG with longer chains (higher molecular weight), e.g. PEG-2000, provides a shielding effect by forming a fixed aqueous layer thickness (FALT) around the surface of the liposome. This layer increases with the increase in PEG molecular weight resulting in the higher stability and longer liposomal circulation time when injected into the bloodstream ${ }^{39-40}$. To our knowledge, there are no reports on the effect of long-chain pegylation and the presence of targeting moieties on the ultrasound-mediated drug release from the liposomes. Therefore, in this study, the mechanical effects generated by lowfrequency pulsed ultrasound at different densities were used to trigger the release of the model drug calcein encapsulated in pegylated and non-pegylated liposomes. In addition, a comparison between the release profiles of pegylated liposomes before and after the conjugation of three moieties (HSA, transferrin and RGD) was conducted.

Human serum albumin (HSA) has a molecular weight of $66.5 \mathrm{kDa}$ and is the most abundant blood protein. This multifunctional protein is synthesized in the liver and plays a significant role in transporting essential molecules including hormones, and fatty acids. It also helps in maintaining a healthy blood osmotic pressure. Cancer cells are continuously stressed due to their harsh tumor microenvironment with a continuous need for oxygen and nutrients necessary for their fast proliferation, migration and survival. However, once the tumor grows to a certain size, it is difficult to acquire sufficient vasculature, oxygen and nutrients. Thus, altered energy metabolism consisting of increased resting energy expenditure associated with an augmented metabolism of sugar, lipid 
and proteins are typical of cancer cells ${ }^{41}$. An alternative to the regular uptake of monomeric amino acids via membrane transport proteins is micropinocytosis, which involves the bulk uptake of proteins such as HSA and the subsequent digestion in lysosomes into free amino acids ${ }^{42}$. A number of studies have reported that albumin receptors (heterogeneous nuclear ribonucleoproteinshnRNP) are localized on the surface of the cancer cells ${ }^{43-45}$. Pegylated liposomes conjugated to HSA have high targeting capabilities and are able to prevent the recognition of the liposomes by antibodies and improve their colloidal stability ${ }^{46-47}$. Albumin is extensively taken up by the tumor cells compared to the uptake by healthy cells in both in vitro ${ }^{48}$ and in vivo studies ${ }^{49}$. Therefore, HSA could be utilized as a suitable targeting ligand to deliver therapeutic drugs to HSA receptors' overexpressed on cancer cells.

Transferrin (Tf) is a serum glycoprotein with a molecular weight of $80 \mathrm{kDa}$. The primary function of $\mathrm{Tf}$ is to regulate the cellular uptake, transport and utilization of iron ${ }^{50}$. Transferrin receptors (TfR) are overexpressed on the surface of many tumors due to the high demand of iron needed for DNA synthesis and cell cycle progression. Thus, Tf receptors are an appealing route for the delivery of drugs into malignant cells. Li et al. ${ }^{51}$ showed that TfR-targeted stealth liposomes, loaded with doxorubicin, enhanced the intracellular uptake of doxorubicin and led to the improved therapeutic efficacy against liver cancer. Another in vitro study by Deshpande et al. ${ }^{50}$ indicated a 3.6-fold increase in the cytotoxicity of TfR-targeted liposomes when compared to conventional liposomes loaded with docetaxel. The work of Zhai et al. ${ }^{52}$ demonstrated that liposomes conjugated with Tf on their surface were an effective delivery system for the chemotherapeutic agent docetaxel.

The tripeptide arginylglycylaspartic acid (RGD) has a molecular weight of 346.34 Da and plays an essential role in cell adhesion systems. It contains a binding site recognized by $\alpha_{v} \beta_{3}$ and $\alpha_{5} \beta_{1}$ 
integrins. These integrins are highly overexpressed on several solid tumors and tumor vasculature ${ }^{53}$. Therefore, targeting these integrins is key in cancer therapy. An earlier study by Nishiya and Sloan ${ }^{54}$ showed that conjugating RGD moieties to the liposomes enhanced their platelet uptake by four-to nine-fold over non-targeted liposomes. Similarly, Chen et al. ${ }^{55}$ developed an RGD-coupled liposomal system which showed a 2.5-fold higher cellular uptake of doxorubicin compared with the unmodified liposomes in the U87MG cell line. These liposomes were internalized by an integrin receptor-mediated endocytic pathway. RGD-coupled stealth liposomes encapsulating Doxorubicin displayed higher accumulation and increased cytotoxicity on melanoma cells compared to the non-targeted liposomes ${ }^{56}$. Other studies have also targeted integrins with RGD-coupled liposomes to develop an effective tumor-targeted delivery system ${ }^{57-}$ 59. 


\section{Materials and methods}

\subsection{Materials}

1,2-dipalmitoyl-sn-glycero-3-phosphocholine (DPPC) and 1,2-distearoyl-sn-glycero-3phosphoethanolamine-N-[amino(polyethylene glycol)-2000] (DSPE-PEG(2000)-NH2) were obtained from Avanti Polar Lipids Inc. (Alabaster, AL, USA). Human serum albumin (HSA), Calcein disodium salt, QuantiPro ${ }^{\mathrm{TM}}$ BCA kit, chloroform, cholesterol, Sephadex ${ }^{\circledR}$ G-100 and 2,4,6 trichloro-1,3,5 triazine (cyanuric chloride), holo-transferrin human and Arginylglycylaspartic acid (RGD) were obtained from Sigma-Aldrich (St. Louis, MO, US, supplied through LABCO LLC. Dubai, UAE).

\subsection{Preparation of non-targeted liposomes}

The liposomes were prepared according to the modified lipid film hydration method described by Lasch et al. ${ }^{60}$. The lipids 1,2-dipalmitoyl-sn-glycero-3-phosphocholine (DPPC), 1,2-distearoyl-snglycero-3-phosphoethanolamine-N-[amino(polyethylene glycol)-2000] (DSPE-PEG(2000)-NH $\mathrm{NH}_{2}$ and cholesterol at a molar ratio of 65:5:30, respectively, were dissolved in chloroform in a round bottom flask. DSPE-PEG(2000)- $\mathrm{NH}_{2}$ was replaced with DPPC for non-pegylated liposomes. A lipid film was formed by removing the chloroform using a rotatory evaporator at $50{ }^{\circ} \mathrm{C}$ for $15 \mathrm{~min}$. The film was then hydrated with $2 \mathrm{~mL}$ of $50 \mathrm{mM}$ calcein (dissolved in phosphate buffer saline (PBS) and the $\mathrm{pH}$ adjusted to 7.4) using the rotatory evaporator for $50 \mathrm{~min}$ at $60{ }^{\circ} \mathrm{C}$ followed by sonication at $60^{\circ} \mathrm{C}$ using a sonication bath (Agar Scientific) for $2 \mathrm{~min}$. The formed liposomes were then extruded at $60{ }^{\circ} \mathrm{C}$ through the $0.2-\mu \mathrm{m}$ polycarbonate membrane using an Avanti ${ }^{\circledR}$ mini- 
extruder (Avanti Polar Lipids, Inc., Alabaster, AL, USA). The liposomes were purified using Sephadex ${ }^{\circledR}$ G-100 gel filtration (size exclusion chromatography) prepared with PBS buffer (pH 7.4). The purified liposomes were collected and stored at $4{ }^{\circ} \mathrm{C}$ until used.

\subsection{Preparation of targeted liposomes}

The covalent conjugation of liposomes to the lysine residues of HSA and transferrin was carried out using cyanuric chloride (2,4,6 trichloro-1,3,5 triazine) as a coupling agent. Cyanuric chloride (CC) was reacted with the liposomes in a 1:1 ratio with the DSPE-PEG- $\mathrm{NH}_{2}$ for 3 hours at $0{ }^{\circ} \mathrm{C}$ (pH 8.5). HSA, Tf, RGD were then added dropwise to the liposomes (final concentration of 0.25 $\mathrm{mg} / \mathrm{mL}, 0.25 \mathrm{mg} / \mathrm{ml}$ and $0.139 \mathrm{mg} / \mathrm{ml}$, respectively) and the reaction was left to stir overnight at room temperature to allow the conjugation to proceed. The unconjugated moieties were then removed using Sephadex ${ }^{\circledR}$ G-100 gel filtration prepared with PBS buffer ( $\left.\mathrm{pH} \sim 7.4\right)$.

\subsection{Measuring the size of the liposomes by Dynamic Light Scattering}

The mean size of the liposomes was determined by Dynamic Light Scattering (DLS) using the DynaPro NanoStar (Wyatt Technology Corp., Santa Barbara, CA, USA) measured at a scattering angle of $90^{\circ}$. The intensity-weighted hydrodynamic radius $(\mathrm{Rh})$ of the diluted liposomes (10 $\mu 1$ in $1 \mathrm{ml} \mathrm{PBS}$ ) was determined at room temperature.

\subsection{Estimation of Phospholipid Content Using Stewart Assay}

The phospholipid content of the liposomes was determined colorimetrically using the Stewart assay ${ }^{61}$. The prepared liposomes were transferred to a round bottom flask and were dried in the 
rotary evaporator under vacuum. Chloroform $(1 \mathrm{~mL})$ was added to the flask followed by sonication for $20 \mathrm{sec} .200 \mu \mathrm{l}$ of the liposomes were then transferred to a Pyrex tube containing $1.8 \mathrm{~mL}$ chloroform. Two $\mathrm{ml}$ of ammonium ferrothiocyanate were added, and the mixture was sonicated for $20 \mathrm{sec}$ followed by centrifugation for $10 \mathrm{~min}$ at $1000 \mathrm{rpm}$. The top dark layer was removed and discarded while the optical density of the bottom clear chloroform layer was measured using UVVIS spectroscopy at $\mathrm{A}_{\max }=485 \mathrm{~nm}$. Three replicates for each sample were used.

\subsection{Imaging of Liposomes by Transmission Electron Microscopy (TEM)}

Samples were prepared by applying a 3- $\mu 1$ drop of the liposomes to a cleaned plasma thin Holey carbon 400-mesh copper grid. After 30 minutes, the excess solution was removed using filter paper blotting. The grid was washed by briefly touching the surface of the grid with a drop ( $30 \mu 1 /$ drop) of deionized water on a Parafilm followed by filter paper blotting. The washing and blotting steps were performed two times, each with a fresh drop of deionized water. A drop (20 $\mu 1 /$ drop) of $1 \%$ (w/v) Uranyl Acetate substitute solution was applied on a Parafilm and the grid was placed facing down on the drop for $30 \mathrm{sec}$. The excess stain was removed and the sample was air-dried at room temperature. The Transmission Electron Microscopy images were obtained using FEI Talos F200X Transmission Electron Microscope (Thermo Fisher Scientific, USA).

\subsection{Protein Quantitation Using Bicinchoninic acid Assay (BCA)}

The colorimetric BCA Protein Assay $^{62}$ was used to confirm the attachment of HSA, RGD and transferrin liposomes. The BCA reagent was prepared by mixing QuantiPro ${ }^{\mathrm{TM}}$ QA buffer: QuantiPro ${ }^{\mathrm{TM}} \mathrm{QB}: \mathrm{CuSO}_{4}$ at a ratio of 25:25:1. $400 \mu \mathrm{l}$ of the liposomes were added to an Eppendorf 
tube containing $600 \mu 1$ PBS buffer, $1 \mathrm{ml}$ of the reagent was added, and the tubes were incubated at $60{ }^{\circ} \mathrm{C}$ for $1 \mathrm{~h}$. The optical density of the samples was measured using UV-VIS spectroscopy at $A_{\max }=562 \mathrm{~nm}$. At least three replicates for each sample were used.

\subsection{Low-Frequency Ultrasound Release Studies (Online Experiments)}

Low-frequency ultrasound (at $20-\mathrm{kHz}$ ) was used to trigger the release of calcein encapsulated in the liposomes. Calcein release was monitored by fluorescence changes using a QuantaMaster QM 30 Spectrofluorometer (Photon Technology International, Edison NJ, USA). Calcein is a fluorescent molecule with excitation and emission wavelengths of $495 \mathrm{~nm}$ and $515 \mathrm{~nm}$, respectively. To prepare the samples in the test cuvette, $75 \mu 1$ of the liposomes were diluted with $3 \mathrm{ml}$ of the PBS buffer. The sonication was then applied using a 20-kHz ultrasonic probe (model VCX750, Sonics \& Materials Inc., Newtown, CT) in a pulsed mode with $20 \mathrm{sec}$ "on" and $10 \mathrm{sec}$ “off” cycles. Different power densities can be produced by the ultrasonic processor, each power density was selected prior to each experiment. The high power densities were found to overheat the samples. Therefore, only three power densities, which triggered calcein release without causing a rise in temperature, were used in this study $\left(6,7\right.$ and $\left.12 \mathrm{~W} / \mathrm{cm}^{2}\right)$. Following sonication, $50 \mu 1$ of $1 \%(\mathrm{v} / \mathrm{v})^{\circ} \mathrm{X}-100$ were added to the samples to lyse the liposomes and release all the encapsulated calcein. Triton X-100 (1\%) is a slandered detergent used for an immediate release of drugs encapsulated inside the liposomes ${ }^{63-64}$. The corresponding fluorescence intensity following the addition of Triton $\mathrm{X}-100$ is characterized as $100 \%$ release $^{65-66}$.

Each sample was placed in the spectrofluorimeter for $4 \mathrm{~min}$ and $10 \mathrm{sec}(50 \mathrm{sec}$ for the baseline with no ultrasound applied $+180 \mathrm{sec}$ for the pulsed sonication $(20 \mathrm{sec}$ "on" and $10 \mathrm{sec}$ off $)+30$ sec after adding Triton X-100). The actual sonication time excluding the off periods is $120 \mathrm{sec}(6$ 
pulses each lasts for $20 \mathrm{sec}$ ). The percentage of calcein release was calculated at a given time using the fluorescence intensity values obtained experimentally according to the following equation,

$$
\% \text { Drug Release }=\frac{F-F_{o}}{F_{T x-100}-F_{o}} \times 100
$$

Where $\mathrm{F}$ is the fluorescence intensity at the time $(\mathrm{t})$ of insonation, $\mathrm{F}_{\mathrm{o}}$ is the average of the initial fluorescence intensity before exposing the sample to the US, and $\mathrm{F}_{\mathrm{TX}-100}$ is the maximum fluorescence achieved after lysing the liposomes using Triton X-100.

\subsection{Estimation of calcein encapsulation inside the liposomes}

The amount of calcein encapsulated inside the liposomes was determined according to Ishii and Nagasaka ${ }^{67}$. Fluorescence readings of diluted liposomes (x40), after gel filtration, were recorded. Fluorescence readings after the addition of Triton X-100 (1\%) to the liposomes were also recorded. Calcein fluorescence was monitored using QuantaMaster QM 30 Spectrofluorometer (Photon Technology International, Edison NJ, USA) with excitation and emission wavelengths of $495 \mathrm{~nm}$ and $515 \mathrm{~nm}$, respectively. The final concentration of the encapsulated calcein was determined using a calibration curve of calcein showing the fluorescence intensity against different concentrations of calcein dissolved in PBS ( $\mathrm{pH}$ 7). The serial dilutions were prepared while maintaining a constant liquid volume in the cuvette (366 nM to $3 \mathrm{mM}$ ). Fluorescence was determined as mentioned above. As seen in Figure 2, the fluorescence value increased with the increase in calcein concentration up to $0.012 \mathrm{mM}$. Then, the fluorescence intensity decreased with the increase in calcein concentration due to calcein self-quenching. 


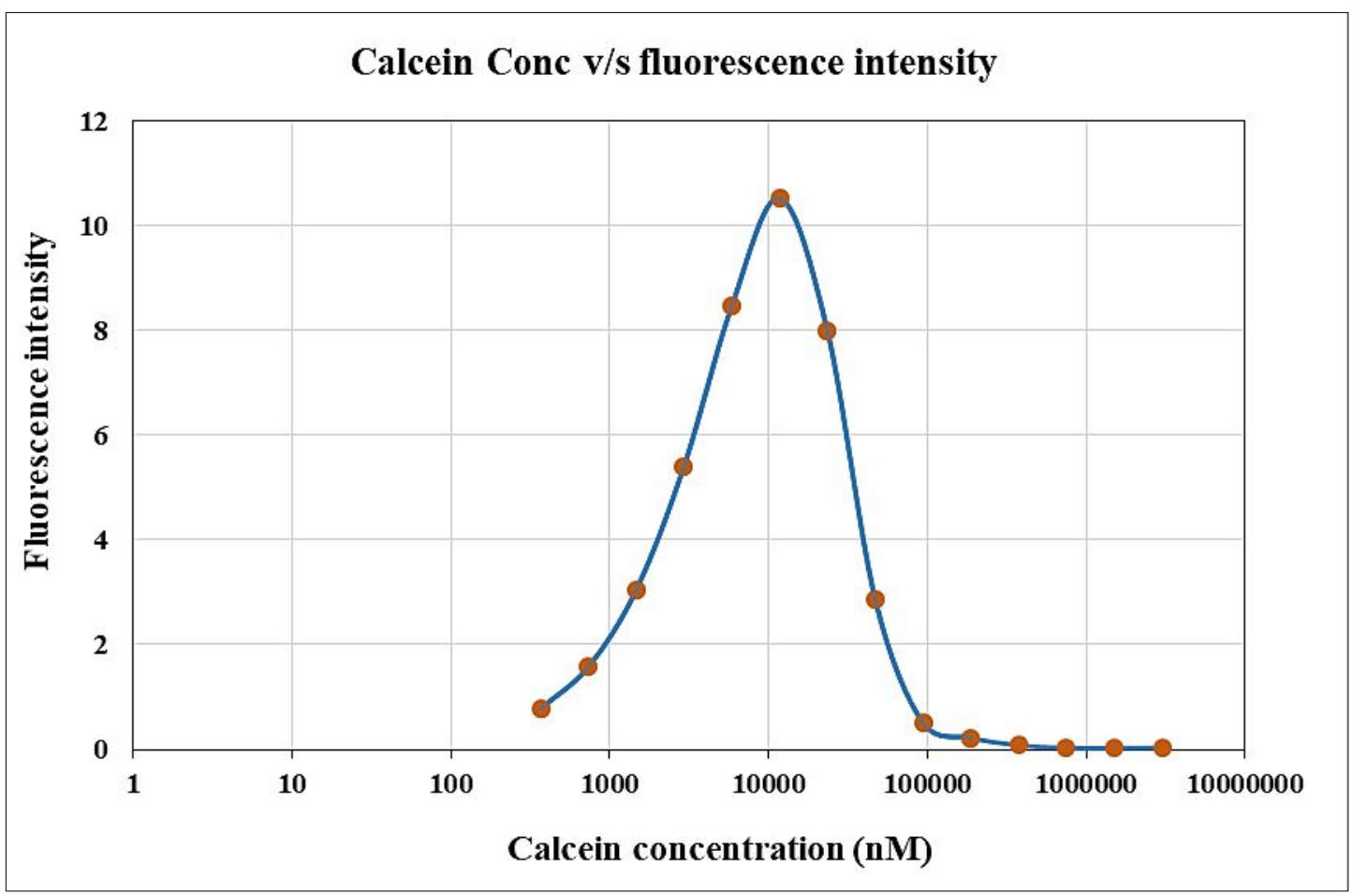

Figure 2. Fluorescence intensity plotted as a function of calcein concentration.

\subsection{Statistical analysis}

All the experiments were run using three different batches of liposomes. The data are reported as the mean with standard error. The differences between the results were compared using a twotailed t-test with the assumption of unequal variances. Two values were considered significantly different when $\mathrm{p} \leq 0.05$. 


\section{Results}

\subsection{Confirming the conjugation of the different moieties to the liposomes}

Liposome-PEG-protein conjugates were prepared by conjugating the HSA amino group $\left(\mathrm{NH}_{2}\right)$, and RGD and Tf molecules to the amino group $\left(\mathrm{NH}_{2}\right)$ present in the DSPE-PEG $\mathrm{P}_{(2000)} \mathrm{NH}_{2}$. Cyanuric chloride was used as a coupling agent with the first chlorine reacting readily at approximately $4{ }^{\circ} \mathrm{C}$, the second at $25^{\circ} \mathrm{C}$, and the third at $80{ }^{\circ} \mathrm{C}$, in an aqueous solution at $\mathrm{pH}$ of 8.5 ${ }^{68}$. As seen in Figure (3), cyanuric chloride reacts with DSPE-PEG-NH $\mathrm{NH}_{2}$ at $4{ }^{\circ} \mathrm{C}(\mathrm{pH}-8.5)$ to produce DSPE-PEG-cyanuric chloride which then reacts with the amine group present in HSA, Tf and RGD at $25^{\circ} \mathrm{C}(\mathrm{pH}-8.5)$ to form DSPE-PEG-cyanuric chloride-protein.

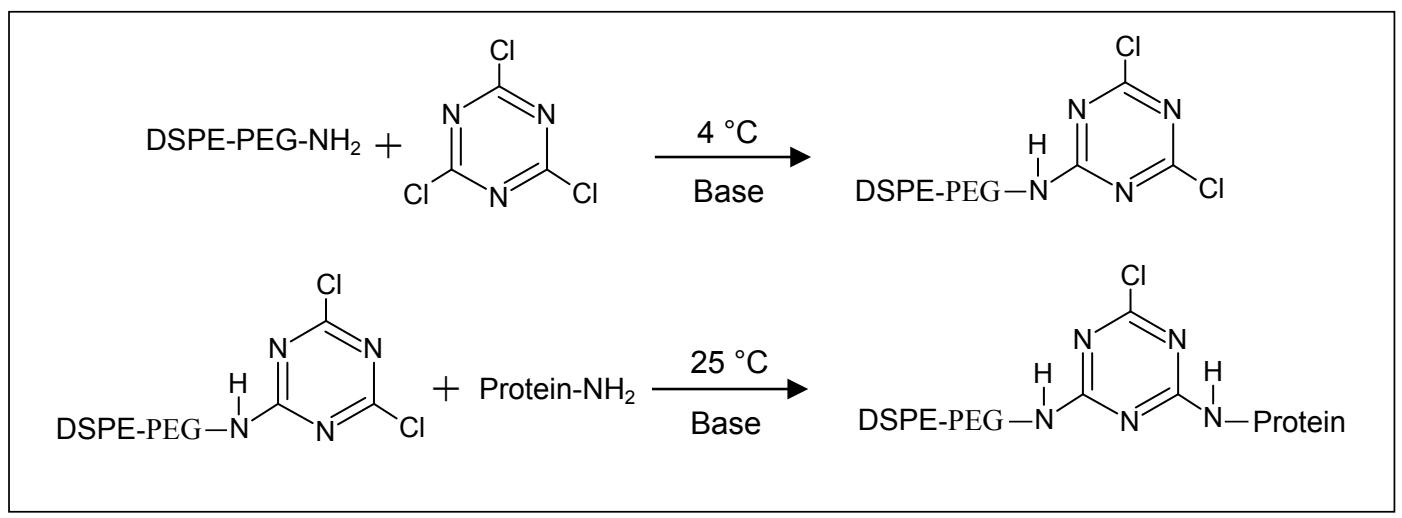

Figure 3. Conjugation of proteins to the liposomes using cyanuric chloride as a coupling agent.

The Stewart assay was used to confirm that both the control and targeted liposomes are at similar lipid concentrations before measuring their protein content. Experimental results showed that the protein content was significantly higher in the HSA, RGD and Tf liposomes compared to the control liposomes, indicating, on average, a 3-fold increase in protein content for HSA $(0.35 \pm 0.006$ $\mu \mathrm{g} / \mathrm{ml}$ for the control liposomes and $1.05 \pm 0.43 \mu \mathrm{g} / \mathrm{ml}$ for the conjugated liposomes, $\mathrm{p}=0.0256$ ). 
Tf-PEG liposomes also showed a 3-fold increase in protein content compare to the control liposomes $(0.646 \pm 0.002 \mu \mathrm{g} / \mathrm{ml}$ and $1.98 \pm 0.012 \mu \mathrm{g} / \mathrm{mL}$ respectively, $\mathrm{p}=0.0174)$. In addition, the protein content of RGD-PEG liposomes was $(2.1 \pm 0.114 \mu \mathrm{g} / \mathrm{ml})$, showing a 5-fold increase compared to the control liposomes $(0.41 \pm 0.008 \mu \mathrm{g} / \mathrm{ml}) \mathrm{p}=0.002$. These results confirm the conjugation of these moieties to the PEG-liposomes.

\subsection{The size of the synthesized liposomes}

On average, the radius of the non-targeted pegylated liposomes (control) was $83.77 \pm 0.91$. The average radius of the HSA-PEG liposomes was $84.86 \pm 1.81 \mathrm{~nm}$. RGD-PEG liposomes showed an average radius of $84.42 \pm 1.50$. The average radius of the Tf-PEG liposomes was $84.70 \pm 1.22$. No significant difference was observed when comparing the control liposomes to the HSA, Tf and RGD conjugated liposomes ( $\mathrm{p}=0.427, \mathrm{p}=0.3497, \mathrm{p}=0.560$ respectively). The average radii of the non-pegylated liposomes was $84.118 \pm 1.44$ showing no significant difference in size compared to the pegylated liposomes $(\mathrm{p}=0.743)$. Thus, all the prepared targeted liposomes were unilamellar structures with diameters less than $200 \mathrm{~nm}$, and are expected to be efficient carriers for drug delivery purposes since they have the ability to make use of the enhanced permeability and retention (EPR) effect due to the defective blood vessels of the growing tumor. Figure 4 shows Transmission Electron Microscopy (TEM) images of calcein-loaded Tf-PEG liposomes. 


\section{3. \\ In \\ vitro}
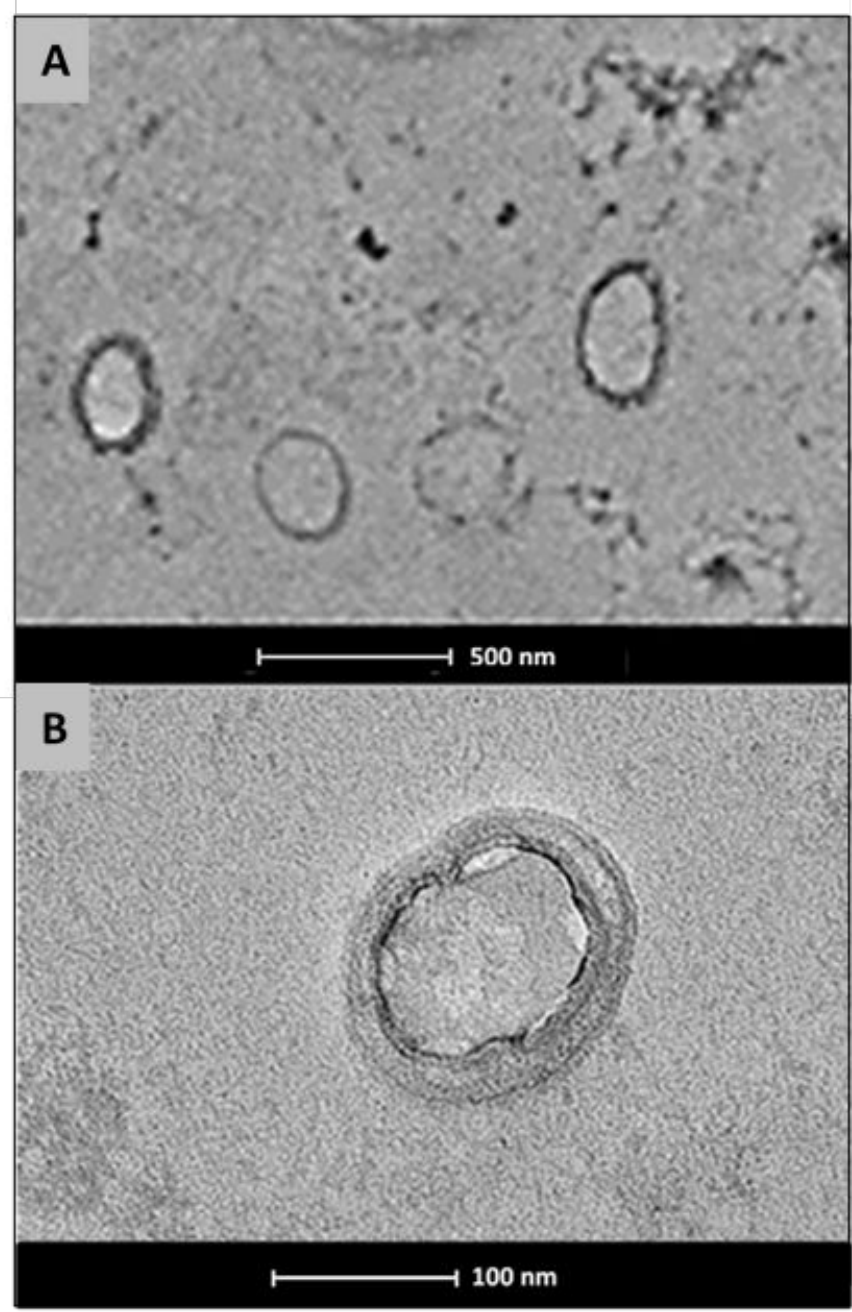

Figure 4. Transmission Electron Microscopy (TEM) images of calcein-loaded Tf-PEG liposomes at $500 \mathrm{~nm}$ scale (A) and $100 \mathrm{~nm}$ scale (B).

\section{release kinetics following insonation with LFUS}

Our results showed that on average, the prepared liposomes encapsulated $1 \mathrm{mM} \pm 0.1$ of calcein inside their hydrophilic core. A calibration curve of calcein fluorescence against concentration showed that at the concentration of $1 \mathrm{mM}$, calcein is self-quenched with no fluorescence properties. Thus, when entrapped inside the liposomes at this concentration, calcein is self-quenched. Therefore, this was used as the baseline. As calcein is released from the liposomes, self-quenching 
is reduced and the fluorescence readings will increase with the increased calcein release from the liposomes $^{69-70}$.

The rate and kinetics of calcein release from the pegylated and non-pegylated liposomes were compared as a function of LFUS ultrasound exposure to a frequency of $20-\mathrm{kHz}$ in a pulsed mode using three different power densities $\left(6,7\right.$ and $\left.12 \mathrm{~W} / \mathrm{cm}^{2}\right)$. To study the effect of pegylation, a comparison of calcein release from pegylated and non-pegylated liposomes was conducted. As shown in Figure (5), calcein release was significantly higher from the pegylated liposomes compared to the non-pegylated liposomes at all the power densities investigated. By the end of the third pulse at the highest power density used $\left(12 \mathrm{~W} / \mathrm{cm}^{2}\right)$, pegylated liposomes released $57.5 \% \pm 4.5$ of the encapsulated calcein while only $22.7 \% \pm 1.7$ was released from the non-pegylated liposomes. Details of the statistical differences between the two types of liposomes are shown in Table 1. 
Figure 5. Percent calcein release from pegylated (control) compared to the non-pegylated liposomes triggered by pulsed 20-kHz LFUS at three power densities $\left(6,7\right.$ and $\left.12 \mathrm{~W} / \mathrm{cm}^{2}\right)$. Results are the average of three liposome batches ( 3 replicates each) (top). Detailed comparison of the percentage releases of calcein encapsulated inside the pegylated and non-pegylated liposomes following the first three pulses at different power densities (bottom). 
To study the effect of the conjugated moieties on calcein release under ultrasound, a comparison between the non-targeted pegylated (control) and targeted pegylated liposomes (RGD-PEG, HSAPEG and Tf-PEG liposomes) was carried out. To ensure that any observed calcein release from the tested liposomes is due to ultrasound exposure, calcein release from non-sonicated liposomes was also recorded. As seen in Figure 6, these liposomes remained intact with no calcein release. The addition of Triton X-100 resulted in releasing all the encapsulated calcein from the non-sonicated liposomes. The recorded final release after lysing the liposomes using Triton X-100 showed that both the non-targeted and targeted liposomes released most of their encapsulated calcein within 4 min of the pulsed LFUS. Interestingly, HSA-PEG liposomes and Tf-PEG liposomes showed a significantly higher rate of calcein release compared to the non-targeted liposomes following the first, the second and the third pulse of all the power densities used $\left(6 \mathrm{~W} / \mathrm{cm}^{2}, 7 \mathrm{~W} / \mathrm{cm}^{2}\right.$ and 12 $\mathrm{W} / \mathrm{cm}^{2}$ ) (Figure 6 and Figure 7).

Following the sonication at the highest investigated power density $\left(12 \mathrm{~W} / \mathrm{cm}^{2}\right)$, calcein release from RGD-PEG liposomes showed no significant difference compared to the control liposomes after the first three pulses (Figure 6 and Figure 7). When exposed to a lower power density (i.e. 7 $\mathrm{W} / \mathrm{cm}^{2}$ ), RGD-PEG liposomes showed more calcein release compared to the control following the first and the third pulses, but no significant change in calcein release was recorded following the second pulse. Sonication at the lowest power density $\left(6 \mathrm{~W} / \mathrm{cm}^{2}\right)$ showed that RGD-PEG liposomes were more sonosensitive compared to the control liposomes releasing significantly more of the encapsulated calcein following the first three pulses. A detailed analysis of the statistical differences between calcein releases from all the liposomes are shown in Table (1). 


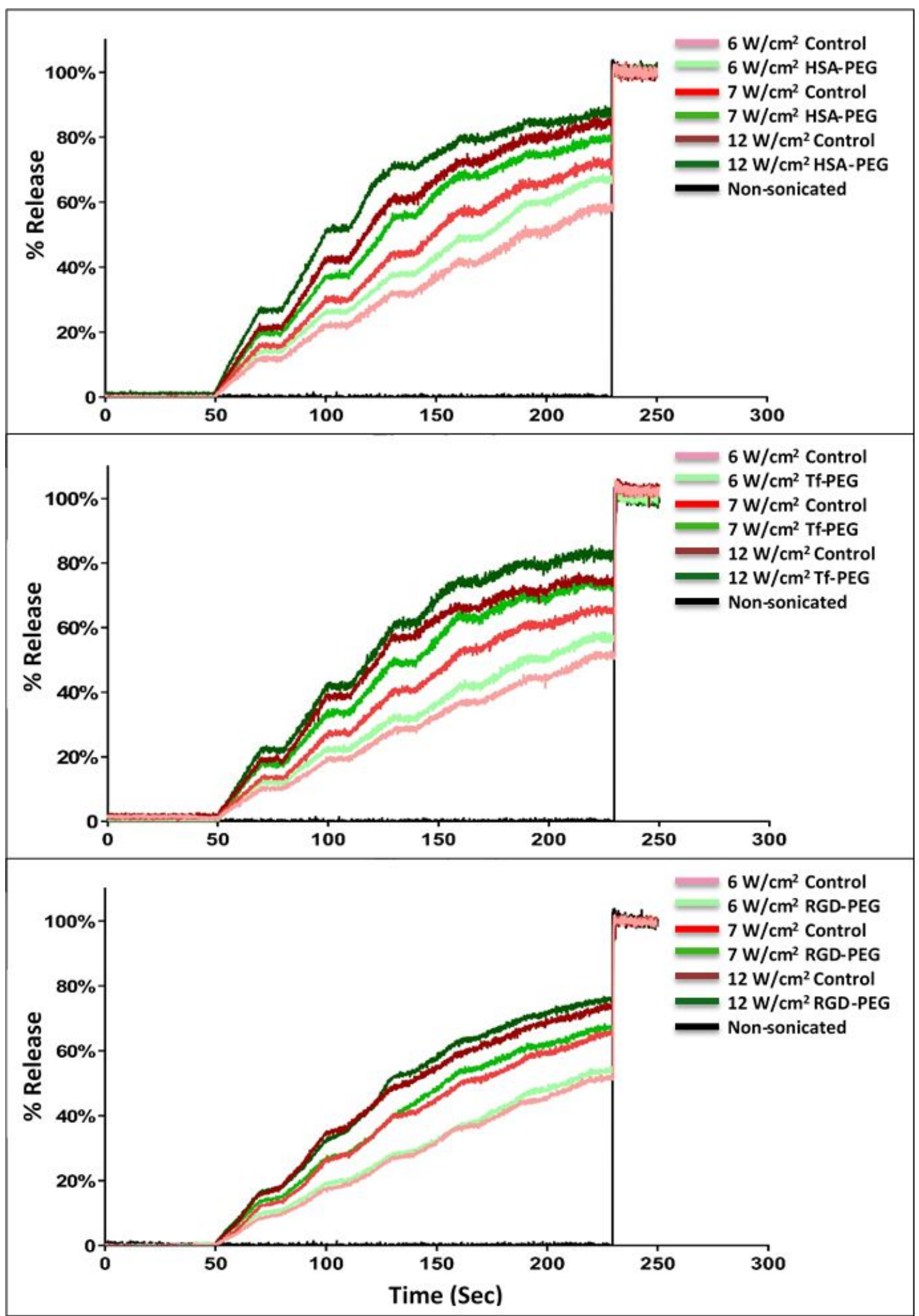

Figure 6. Percent calcein release from non-targeted (control) compared to HSA-PEG, Tf-PEG and RGD-PEG liposomes triggered by pulsed $20-\mathrm{kHz}$ LFUS for 4 min and $10 \mathrm{sec}$ at three power densities $\left(6,7\right.$ and $\left.12 \mathrm{~W} / \mathrm{cm}^{2}\right)$. Non-sonicated liposomes showed no calcein release. Results are the average of three liposome batches ( 3 replicates each). 


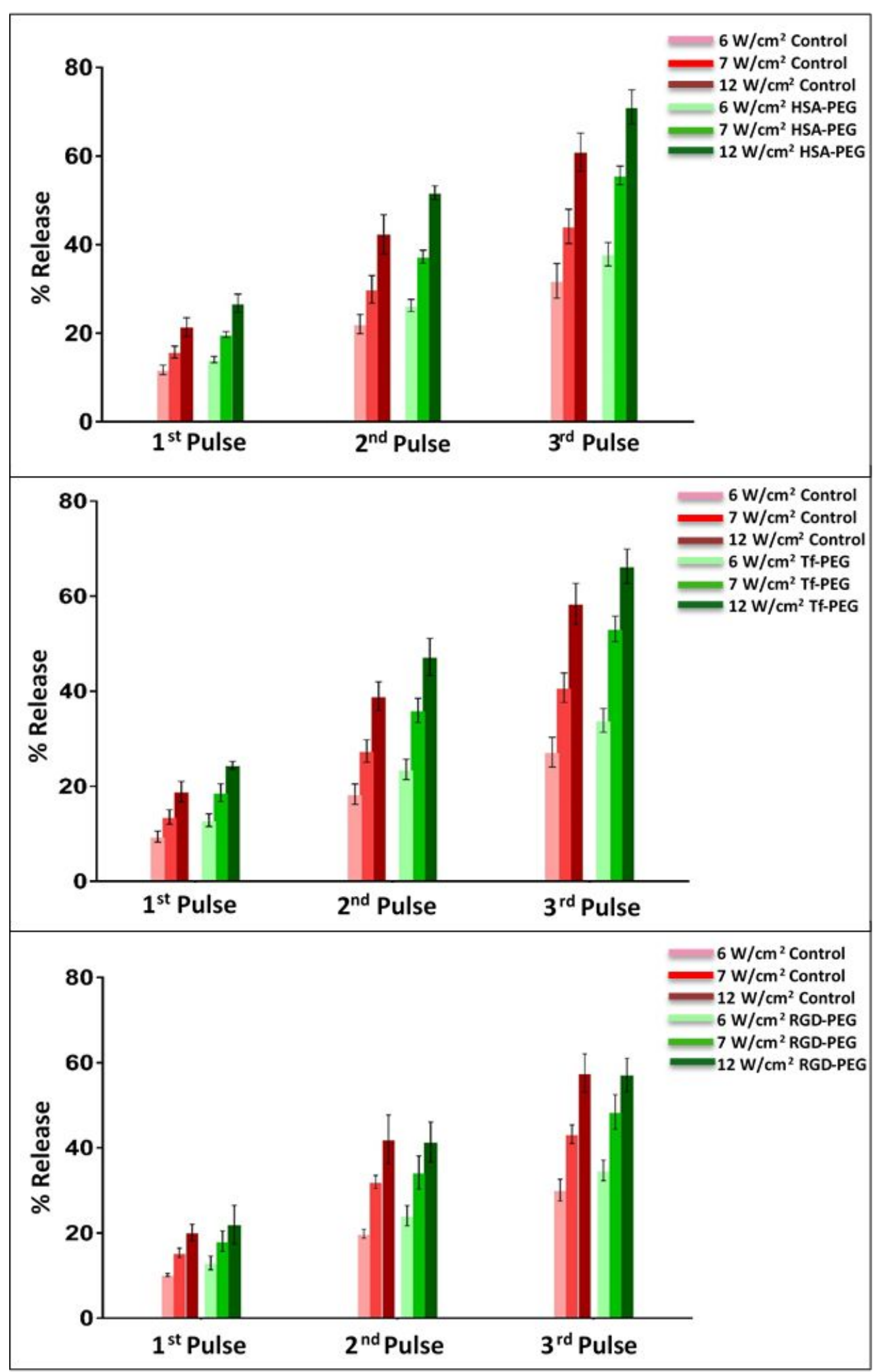

Figure 7. A comparison between the percentage releases of calcein encapsulated inside the control and targeted liposomes (HSA-PEG, Tf-PEG and RGD-PEG) following the first three $20-\mathrm{kHz}$ pulses at different power densities $\left(6 \mathrm{~W} / \mathrm{cm}^{2}, 7 \mathrm{~W} / \mathrm{cm}^{2}\right.$, and $\left.12 \mathrm{~W} / \mathrm{cm}^{2}\right)$. 
Table 1. The statistical difference (P-value) of calcein release between the control (non-targeted pegylated liposomes) and the targeted (HSA-PEG, Tf-PEG and RGD-PEG), as well as, the nonpegylated liposomes following the first three pulses of LFUS $(20-\mathrm{kHz})$ at different power densities $\left(6 \mathrm{~W} / \mathrm{cm}^{2}, 7 \mathrm{~W} / \mathrm{cm}^{2}\right.$ and $\left.12 \mathrm{~W} / \mathrm{cm}^{2}\right)$.

\begin{tabular}{|c|c|c|c|c|}
\cline { 3 - 5 } \multicolumn{2}{c|}{} & \multicolumn{3}{c|}{$\begin{array}{c}\text { Statistical difference in calcein release following the } \\
\text { first three pulses compared to the control (p-value) }\end{array}$} \\
\hline \multirow{3}{*}{ Liposomes } & Power Density & First Pulse & Second Pulse & Third Pulse \\
\hline \multirow{3}{*}{ HSA-PEG } & $6 \mathrm{~W} / \mathrm{cm}^{2}$ & 0.00335 & 0.01056 & 0.01901 \\
\cline { 2 - 5 } & $7 \mathrm{~W} / \mathrm{cm}^{2}$ & 0.00001 & 0.00029 & 0.00002 \\
\cline { 2 - 6 } & $12 \mathrm{~W} / \mathrm{cm}^{2}$ & 0.00035 & 0.00015 & 0.00013 \\
\hline \multirow{3}{*}{ Tf-PEG } & $6 \mathrm{~W} / \mathrm{cm}^{2}$ & 0.00029 & 0.00054 & 0.00070 \\
\cline { 2 - 6 } & $7 \mathrm{~W} / \mathrm{cm}^{2}$ & 0.00124 & 0.00036 & 0.00005 \\
\cline { 2 - 6 } & $12 \mathrm{~W} / \mathrm{cm}^{2}$ & 0.00033 & 0.00374 & 0.01077 \\
\hline \multirow{3}{*}{ RGD-PEG } & $6 \mathrm{~W} / \mathrm{cm}^{2}$ & 0.00347 & 0.00450 & 0.01500 \\
\cline { 2 - 6 } & $7 \mathrm{~W} / \mathrm{cm}^{2}$ & 0.04384 & 0.26515 & 0.02933 \\
\cline { 2 - 6 } Non- & $12 \mathrm{~W} / \mathrm{cm}^{2}$ & 0.41226 & 0.84810 & 0.87313 \\
\cline { 2 - 6 } PEGylated & $6 \mathrm{~W} / \mathrm{cm}^{2}$ & 0.000004 & 0.0000004 & 0.00000065 \\
\cline { 2 - 6 } & $7 \mathrm{~W} / \mathrm{cm}^{2}$ & 0.000003 & 0.0000001 & 0.00000002 \\
\hline & $12 \mathrm{~W} / \mathrm{cm}^{2}$ & 0.000019 & 0.0000001 & 0.00000001 \\
\hline
\end{tabular}




\section{Discussion}

Active/Ligand targeting is a promising technique for the safe and efficient delivery of chemotherapy drugs to the tumor site. The energy generated by the ultrasound waves triggers the release of the encapsulated drugs from these liposomes in a controlled manner. In this study, the acoustic release of the model drug calcein encapsulated inside different targeted liposomes was compared. Our results showed that the synthesized liposomes, before and after the conjugation to HSA, Tf or RGD, were less than $200 \mathrm{~nm}$ in diameter making them small unilamellar vesicles (SUV). This will allow the extravasation of these targeted liposomes through the leaky vessels into the tumor, but not into the healthy tissues.

The ability of the ultrasound to trigger calcein release depends on reaching the cavitation threshold, i.e., the power at which the negative pressure peak of the ultrasonic wave exceeds the tensile strength of the buffer ${ }^{71}$. The formed bubbles will oscillate in the acoustic field and ultimately collapse. This will generate sonic shock waves. The energy produced from these shock waves enhances the permeability of the liposomes (Figure 8).

The main parameters of concern in ultrasound triggered release from liposomes are the frequency, pulse duration, and intensity. When high-frequency ultrasound is used, it produces thermal or mechanical effects. The intensity level of the ultrasound varies depending on the application. While low intensity triggers drug release by inducing mild cavitation, high intensity either triggers drug release due to the temperature increase or strong cavitation events ${ }^{28,72}$.

LFUS is used in drug delivery due to its ability to enhance the membrane permeability, thus enhancing drug and gene delivery into the cells ${ }^{73}$. Liposomes have a similar structure to that of biological membranes, applying LFUS increases the permeability of the liposomes triggering the release of the entrapped drugs in a controlled manner ${ }^{30,74}$. 
All the power intensities used in this study were sufficient to reach the cavitation threshold. Our results showed that, with both the control and targeted liposomes, the increase in fluorescence following ultrasound application is attributed to calcein release from liposomes and the consequent relief of self-quenching. The fluorescence increase freezes during the "off" period of sonication suggesting that the ultrasound effect was not caused by the damage or oxidation of the lipids.

The mechanical effect generated by the acoustic wave of the LFUS is likely to be the main trigger of calcein release from the control and targeted liposomes tested in this study. However, the high energy generated by the cavitation process resulted in a temperature rise by the end of the third pulse at the highest power density used (from $25{ }^{\circ} \mathrm{C}$ to $31{ }^{\circ} \mathrm{C}$ ). Although this rise in temperature 
is still below the transition temperature of the DPPC $\left(41.3{ }^{\circ} \mathrm{C}\right)$, this does not eliminate a possible thermal effect capable of enhancing the release which is mainly driven by the mechanical effect of the LFUS. Previous studies have shown that ultrasonic absorbance by the lipid bilayer occurs during lipid phase transition, while the absorbance by the membrane is diminishing below the phase transition bilayer ${ }^{75-76}$. This suggests that liposomal drug release, achieved when working below the phase transition temperature is attributed to mechanical and possible thermal effects due to the rise in temperature rather than absorbance of ultrasound by the lipids.

Earlier studies have shown that transient cavitation produces extreme shear forces which result in freeing some fragments of the phospholipids bilayer ${ }^{19,77-78}$. However, when the hydrophobic part of the phospholipids is exposed to the aqueous medium, a re-fusion of the phospholipids bilayer occurs fairly quickly forming new smaller liposomes (mainly small unilamellar vesicles (SUV)) ${ }^{79-}$ 82. In this study, we have shown that the presence of PEG on the surface of the liposomes enhanced the ability of low-frequency ultrasound $(20-\mathrm{kHz})$ to permeabilize these liposomes and release the fluorescent agent, which is in agreement with previous studies reporting that pegylation enhances the sonosensitivity of the liposomes ${ }^{24,77,83}$. Pegylated liposomes exposed to LFUS are transformed to both (1) smaller liposomes, with no change to their chemical integrity, and (2) much smaller non-liposomal un-specified fractions ${ }^{24,84-85}$. This explains the coexistence of liposome-forming lipids (such as PCs) with micelle-forming lipids such as DSPE-PEG ${ }^{24}$.

According to Garbuzenko et al. ${ }^{86}$, liposomes-forming lipids, including DPPC, have packing parameters of 0.74-1.0 while the DSPE-PEG has a lower packing parameter of 0.5. In addition, DSPE-PEG has a higher critical aggregation concentration (CAC) than liposome-forming lipids ( 10-5 M for PEG-lipids, and $\sim 10-10 \mathrm{M}$ for zwitterionic phospholipids $)^{24,} 28,87-89$. These two characteristics of DSPE-PEG make it more likely for this polymer to be ejected out of the 
phospholipids bilayer to form micelles upon exposure to ultrasound waves. The enhanced pegylated liposomal sonosensitivity recorded here, with both HSA-PEG and Tf-PEG liposomes compared to the control liposomes, could be due to the fact that HSA and Tf will add more weight to the PEG molecules ( $\mathrm{MW}=66.5 \mathrm{KDa}$ and $80 \mathrm{KDa}$, respectively) which increases the chance for the PEG molecules to leap out of the phospholipids bilayer, forming more micelles and releasing more calcein. RGD liposomes were not as efficient in enhancing the sonosensitivity compared to HSA and Tf possibly due to the smaller size of RGD (346.34 Da).

\section{Conclusion}

In summary, the present study clearly indicated that pegylation enhances the sonosensitivity of the liposomes when exposed to pulsed low-frequency ultrasound (at 20-kHz) with pegylated liposomes releasing $153.3 \%$ more than non-pegylated liposomes. We showed that the modification of pegylated liposome with HSA, Tf and RGD had no significant effect on the size of the liposomes $(\mathrm{p}=0.427, \mathrm{p}=0.3497, \mathrm{p}=0.560$ respectively). HSA-PEG liposomes and Tf-PEG liposomes were more sonosensitive compared to the control liposomes showing significantly higher calcein release following the exposure to pulsed LFUS ( $p \geq 0.05)$. Thus, adding more benefits to their targeting efficacy.

\section{Acknowledgement}

This work was financially supported by the American University of Sharjah Faculty Research Grants, Al-Jalila Foundation (AJF 2015555), Al Qasimi Foundation, Patient's Friends CommitteeSharjah, the Biosciences and Bioengineering Research Institute (BBRI18-CEN-11) and the Dana 
Gas Endowed Chair for Chemical Engineering. We also would like to acknowledge the TEM facility of the Core Technology Platform Resources at New York University, Abu Dhabi and Dr. Renu Pasricha for her help with the TEM images.

\section{Author Contributions}

The manuscript was written through contributions of all authors. All authors have given approval to the final version of the manuscript.

\section{Conflict of Interest Disclosure}

The authors declare no competing financial interest. 


\section{References}

1. McKnight, J. A., Principles of chemotherapy. Clinical Techniques in Small Animal Practice 2003, 18 (2), 67-72. DOI: https://doi.org/10.1053/svms.2003.36617.

2. Bhushan, B.; Khanadeev, V.; Khlebtsov, B.; Khlebtsov, N.; Gopinath, P., Impact of albumin based approaches in nanomedicine: Imaging, targeting and drug delivery. Advances in colloid and interface science 2017, 246, 13-39. DOI: 10.1016/j.cis.2017.06.012.

3. Uchegbu, I. F.; Siew, A., Nanomedicines and nanodiagnostics come of age. Journal of pharmaceutical sciences 2013, 102 (2), 305-10. DOI: 10.1002/jps.23377.

4. Rohilla, S.; Chauhan, C.; Singh, R.; Rohilla, A.; Kaushik, D.; Sardana, S.; Dureja, H., Liposomes:Preparations and Applications. International Journal of Drug Development and Research 2012, 4 (4), 108-115.

5. Allen, T. M.; Cullis, P. R., Liposomal drug delivery systems: from concept to clinical applications. Adv Drug Deliv Rev 2013, 65 (1), 36-48. DOI: 10.1016/j.addr.2012.09.037.

6. Lee, J. H.; Lee, H. B.; Andrade, J. D., Blood compatibility of polyethylene oxide surfaces. Progress in Polymer Science 1995, 20 (6), 1043-1079. DOI: https://doi.org/10.1016/0079-6700(95)00011-4.

7. Sofia, S. J.; Premnath, V.; Merrill, E. W., Poly(ethylene oxide) Grafted to Silicon Surfaces: Grafting Density and Protein Adsorption. Macromolecules 1998, 31 (15), 5059-5070. DOI: 10.1021/ma971016I.

8. Alcantar, N. A.; Aydil, E. S.; Israelachvili, J. N., Polyethylene glycol-coated biocompatible surfaces. Journal of Biomedical Materials Research 2000, 51 (3), 343-351. DOI: 10.1002/10974636(20000905)51:3<343::AID-JBM7>3.0.CO;2-D.

9. Nag, O. K.; Awasthi, V., Surface engineering of liposomes for stealth behavior. Pharmaceutics 2013, 5 (4), 542-69. DOI: 10.3390/pharmaceutics5040542.

10. Zetter, B. R., Angiogenesis and tumor metastasis. Annu Rev Med 1998, 49, 407-24. DOI: 10.1146/annurev.med.49.1.407.

11. Dvorak, H. F.; Brown, L. F.; Detmar, M.; Dvorak, A. M., Vascular permeability factor/vascular endothelial growth factor, microvascular hyperpermeability, and angiogenesis. The American journal of pathology 1995, 146 (5), 1029-1039.

12. Greish, K., Enhanced permeability and retention effect for selective targeting of anticancer nanomedicine: are we there yet? Drug Discovery Today: Technologies 2012, 9 (2), e161-e166. DOI: https://doi.org/10.1016/j.ddtec.2011.11.010.

13. Aggarwal, P.; Hall, J. B.; McLeland, C. B.; Dobrovolskaia, M. A.; McNeil, S. E., Nanoparticle interaction with plasma proteins as it relates to particle biodistribution, biocompatibility and therapeutic efficacy. Adv Drug Deliv Rev 2009, 61 (6), 428-37. DOI: 10.1016/j.addr.2009.03.009.

14. Hu, C. M.; Kaushal, S.; Tran Cao, H. S.; Aryal, S.; Sartor, M.; Esener, S.; Bouvet, M.; Zhang, L., Halfantibody functionalized lipid-polymer hybrid nanoparticles for targeted drug delivery to carcinoembryonic antigen presenting pancreatic cancer cells. Molecular pharmaceutics 2010, 7 (3), 914-20. DOI: 10.1021/mp900316a.

15. Turk, M. J.; Reddy, J. A.; Chmielewski, J. A.; Low, P. S., Characterization of a novel pH-sensitive peptide that enhances drug release from folate-targeted liposomes at endosomal pHs. Biochimica et biophysica acta 2002, 1559 (1), 56-68.

16. O'Brien, D. F.; Whitesides, T. H.; Klingbiel, R. T., The photopolymerization of lipid-diacetylenes in bimolecular-layer membranes. Journal of Polymer Science: Polymer Letters Edition 1981, 19 (3), 95-101. DOI: 10.1002/pol.1981.130190302.

17. Zhu, L.; Kate, P.; Torchilin, V. P., Matrix metalloprotease 2-responsive multifunctional liposomal nanocarrier for enhanced tumor targeting. ACS Nano 2012, 6 (4), 3491-8. DOI: 10.1021/nn300524f. 
18. Needham, D.; Anyarambhatla, G.; Kong, G.; Dewhirst, M. W., A new temperature-sensitive liposome for use with mild hyperthermia: characterization and testing in a human tumor xenograft model. Cancer research 2000, 60 (5), 1197-201.

19. Pitt, W. G.; Husseini, G. A.; Staples, B. J., Ultrasonic Drug Delivery - A General Review. Expert opinion on drug delivery 2004, 1 (1), 37-56. DOI: 10.1517/17425247.1.1.37.

20. Ahmed, S. E.; Awad, N.; Paul, V.; Moussa, H. G.; Husseini, G. A., Improving the Efficacy of Anticancer Drugs via Encapsulation and Acoustic Release. Current topics in medicinal chemistry 2018, 18 (10), 857-880. DOI: 10.2174/1568026618666180608125344.

21. Udroiu, I., Ultrasonic drug delivery in Oncology. Journal of B.U.ON. : official journal of the Balkan Union of Oncology 2015, 20 (2), 381-90.

22. Graham, S. M.; Carlisle, R.; Choi, J. J.; Stevenson, M.; Shah, A. R.; Myers, R. S.; Fisher, K.; Peregrino, M. B.; Seymour, L.; Coussios, C. C., Inertial cavitation to non-invasively trigger and monitor intratumoral release of drug from intravenously delivered liposomes. Journal of controlled release : official journal of the Controlled Release Society 2014, 178, 101-7. DOI: 10.1016/j.jconrel.2013.12.016.

23. Husseini, G. A.; Myrup, G. D.; Pitt, W. G.; Christensen, D. A.; Rapoport, N. Y., Factors affecting acoustically triggered release of drugs from polymeric micelles. J Control Release 2000, 69 (1), 43-52.

24. Schroeder, A.; Avnir, Y.; Weisman, S.; Najajreh, Y.; Gabizon, A.; Talmon, Y.; Kost, J.; Barenholz, Y., Controlling liposomal drug release with low frequency ultrasound: mechanism and feasibility. Langmuir 2007, 23 (7), 4019-25. DOI: 10.1021/la0631668.

25. Pangu, G. D.; Davis, K. P.; Bates, F. S.; Hammer, D. A., Ultrasonically induced release from nanosized polymer vesicles. Macromol Biosci 2010, 10 (5), 546-54. DOI: 10.1002/mabi.201000081.

26. Salkho, N. M.; Paul, V.; Kawak, P.; Vitor, R. F.; Martins, A. M.; Al Sayah, M.; Husseini, G. A., Ultrasonically controlled estrone-modified liposomes for estrogen-positive breast cancer therapy. Artificial Cells, Nanomedicine, and Biotechnology 2018, 1-11. DOI: 10.1080/21691401.2018.1459634.

27. D, C. L. Ultrasound for targeted delivery of cytotoxic drugs from liposomes. M.Sc. Thesis, Ben Gurion University, Beer Sheva, Israel, 2000.

28. Schroeder, A.; Kost, J.; Barenholz, Y., Ultrasound, liposomes, and drug delivery: principles for using ultrasound to control the release of drugs from liposomes. Chem Phys Lipids 2009, 162 (1-2), 1-16. DOI: 10.1016/j.chemphyslip.2009.08.003.

29. Hansen, Y.; Davies, C. d. L.; Afadzi, M.; Angelsen, B.; Johansen, T.; Nilssen, E. A. In Ultrasonic drug release: Impact on liposomal doxorubicin in collagen gels, 2012 IEEE International Ultrasonics Symposium, 7-10 Oct. 2012; 2012; pp 425-428. DOI: 10.1109/ULTSYM.2012.0105.

30. Pitt, W. G.; Husseini, G. A.; Roeder, B. L.; Dickinson, D. J.; Warden, D. R.; Hartley, J. M.; Jones, P. W., Preliminary results of combining low frequency low intensity ultrasound and liposomal drug delivery to treat tumors in rats. Journal of nanoscience and nanotechnology 2011, 11 (3), 1866-70.

31. Yang, F. Y.; Wong, T. T.; Teng, M. C.; Liu, R. S.; Lu, M.; Liang, H. F.; Wei, M. C., Focused ultrasound and interleukin-4 receptor-targeted liposomal doxorubicin for enhanced targeted drug delivery and antitumor effect in glioblastoma multiforme. J Control Release 2012, 160 (3), 652-8. DOI: 10.1016/j.jconrel.2012.02.023.

32. Afadzi, M.; Strand, S. P.; Nilssen, E. A.; Masoy, S. E.; Johansen, T. F.; Hansen, R.; Angelsen, B. A.; de, L. D. C., Mechanisms of the ultrasound-mediated intracellular delivery of liposomes and dextrans. IEEE Trans Ultrason Ferroelectr Freq Control 2013, 60 (1), 21-33. DOI: 10.1109/tuffc.2013.2534.

33. Eggen, S.; Afadzi, M.; Nilssen, E. A.; Haugstad, S. B.; Angelsen, B.; Davies, C. d. L. In Ultrasound mediated delivery of liposomal doxorubicin in prostate tumor tissue, 2012 IEEE International Ultrasonics Symposium, 7-10 Oct. 2012; 2012; pp 436-439. DOI: 10.1109/ULTSYM.2012.0108.

34. Santos, M. A.; Goertz, D. E.; Hynynen, K., Focused Ultrasound Hyperthermia Mediated Drug Delivery Using Thermosensitive Liposomes and Visualized With in vivo Two-Photon Microscopy. Theranostics 2017, 7 (10), 2718-2731. DOI: 10.7150/thno.19662. 
35. Um, W.; Kwon, S.; You, D. G.; Cha, J. M.; Kim, H. R.; Park, J. H., Non-thermal acoustic treatment as a safe alternative to thermosensitive liposome-involved hyperthermia for cancer therapy. RSC Advances 2017, 7 (47), 29618-29625. DOI: 10.1039/C7RA02065A.

36. Chen, S.; Shohet, R. V.; Bekeredjian, R.; Frenkel, P.; Grayburn, P. A., Optimization of ultrasound parameters for cardiac gene delivery of adenoviral or plasmid deoxyribonucleic acid by ultrasoundtargeted microbubble destruction. J Am Coll Cardiol 2003, 42 (2), 301-8.

37. Chen, S.; Ding, J.-h.; Bekeredjian, R.; Yang, B.-z.; Shohet, R. V.; Johnston, S. A.; Hohmeier, H. E.; Newgard, C. B.; Grayburn, P. A., Efficient gene delivery to pancreatic islets with ultrasonic microbubble destruction technology. Proceedings of the National Academy of Sciences of the United States of America 2006, 103 (22), 8469-8474. DOI: 10.1073/pnas.0602921103.

38. Sugiyama, I.; Sadzuka, Y., Correlation of fixed aqueous layer thickness around PEG-modified liposomes with in vivo efficacy of antitumor agent-containing liposomes. Curr Drug Discov Technol 2011, $8(4), 357-66$.

39. Sugiyama, I.; Sadzuka, Y., Change in the character of liposomes as a drug carrier by modifying various polyethyleneglycol-lipids. Biol Pharm Bull 2013, 36 (6), 900-6.

40. Hashizaki, K.; Taguchi, H.; Itoh, C.; Sakai, H.; Abe, M.; Saito, Y.; Ogawa, N., Effects of poly(ethylene glycol) (PEG) concentration on the permeability of PEG-grafted liposomes. Chem Pharm Bull (Tokyo) 2005, 53 (1), 27-31.

41. Fadaka, A.; Ajiboye, B.; Ojo, O.; Adewale, O.; Olayide, I.; Emuowhochere, R., Biology of glucose metabolization in cancer cells. Journal of Oncological Sciences 2017, 3 (2), 45-51. DOI: https://doi.org/10.1016/j.jons.2017.06.002.

42. Kamphorst, J. J.; Nofal, M.; Commisso, C.; Hackett, S. R.; Lu, W.; Grabocka, E.; Vander Heiden, M. G.; Miller, G.; Drebin, J. A.; Bar-Sagi, D.; Thompson, C. B.; Rabinowitz, J. D., Human pancreatic cancer tumors are nutrient poor and tumor cells actively scavenge extracellular protein. Cancer research 2015, 75 (3), 544-53. DOI: 10.1158/0008-5472.Can-14-2211.

43. Fritzsche, T.; Schnölzer, M.; Fiedler, S.; Weigand, M.; Wiessler, M.; Frei, E., Isolation and identification of heterogeneous nuclear ribonucleoproteins (hnRNP) from purified plasma membranes of human tumour cell lines as albumin-binding proteins. Biochemical Pharmacology 2004, 67 (4), 655-665. DOI: https://doi.org/10.1016/j.bcp.2003.09.027.

44. Satoh, H.; Kamma, H.; Ishikawa, H.; Horiguchi, H.; Fujiwara, M.; Yamashita, Y. T.; Ohtsuka, M.; Sekizawa, K., Expression of hnRNP A2/B1 proteins in human cancer cell lines. International journal of oncology 2000, 16 (4), 763-7.

45. Tockman, M. S.; Gupta, P. K.; Myers, J. D.; Frost, J. K.; Baylin, S. B.; Gold, E. B.; Chase, A. M.; Wilkinson, P. H.; Mulshine, J. L., Sensitive and specific monoclonal antibody recognition of human lung cancer antigen on preserved sputum cells: a new approach to early lung cancer detection. Journal of clinical oncology : official journal of the American Society of Clinical Oncology 1988, 6 (11), 1685-93. DOI: 10.1200/jco.1988.6.11.1685.

46. Mariam, J.; Sivakami, S.; Dongre, P. M., Albumin corona on nanoparticles - a strategic approach in drug delivery. Drug delivery 2016, 23 (8), 2668-2676. DOI: 10.3109/10717544.2015.1048488.

47. Furumoto, K.; Yokoe, J.; Ogawara, K.; Amano, S.; Takaguchi, M.; Higaki, K.; Kai, T.; Kimura, T., Effect of coupling of albumin onto surface of PEG liposome on its in vivo disposition. International journal of pharmaceutics 2007, 329 (1-2), 110-6. DOI: 10.1016/j.ijpharm.2006.08.026.

48. Germain, P.; Metezeau, P.; Hellio, R.; Habrioux, G., Internalization and biological effects of serum albumin in the breast cancer MCF-7 and MDA-MB 231 cells. Cellular and molecular biology (Noisy-leGrand, France) 1995, 41 (8), 1119-29.

49. Stehle, G.; Sinn, H.; Wunder, A.; Schrenk, H. H.; Schutt, S.; Maier-Borst, W.; Heene, D. L., The loading rate determines tumor targeting properties of methotrexate-albumin conjugates in rats. Anticancer drugs 1997, 8 (7), 677-85. 
50. Deshpande, P. P.; Biswas, S.; Torchilin, V. P., Current trends in the use of liposomes for tumor targeting. Nanomedicine (London, England) 2013, 8 (9), 1509-28. DOI: 10.2217/nnm.13.118.

51. Li, X.; Ding, L.; Xu, Y.; Wang, Y.; Ping, Q., Targeted delivery of doxorubicin using stealth liposomes modified with transferrin. International journal of pharmaceutics 2009, 373 (1-2), 116-23. DOI: 10.1016/j.ijpharm.2009.01.023.

52. Zhai, G.; Wu, J.; Yu, B.; Guo, C.; Yang, X.; Lee, R. J., A transferrin receptor-targeted liposomal formulation for docetaxel. Journal of nanoscience and nanotechnology 2010, 10 (8), 5129-36.

53. Ruoslahti, E., RGD and other recognition sequences for integrins. Annual review of cell and developmental biology 1996, 12, 697-715. DOI: 10.1146/annurev.cellbio.12.1.697.

54. Nishiya, T.; Sloan, S., Interaction of RGD liposomes with platelets. Biochemical and biophysical research communications 1996, 224 (1), 242-5. DOI: 10.1006/bbrc.1996.1014.

55. Chen, Z.; Deng, J.; Zhao, Y.; Tao, T., Cyclic RGD peptide-modified liposomal drug delivery system: enhanced cellular uptake in vitro and improved pharmacokinetics in rats. International journal of nanomedicine 2012, 7, 3803-11. DOI: 10.2147/ijn.S33541.

56. Xiong, X. B.; Huang, Y.; Lu, W. L.; Zhang, X.; Zhang, H.; Nagai, T.; Zhang, Q., Intracellular delivery of doxorubicin with RGD-modified sterically stabilized liposomes for an improved antitumor efficacy: in vitro and in vivo. Journal of pharmaceutical sciences 2005, 94 (8), 1782-93. DOI: 10.1002/jps.20397.

57. Du, H.; Cui, C.; Wang, L.; Liu, H.; Cui, G., Novel tetrapeptide, RGDF, mediated tumor specific liposomal doxorubicin (DOX) preparations. Molecular pharmaceutics 2011, 8 (4), 1224-32. DOI: $10.1021 / \mathrm{mp200039s.}$

58. Knudsen, N. Ø.; Schiffelers, R. M.; Jorgensen, L.; Hansen, J.; Frokjaer, S.; Foged, C., Design of cyclic RKKH peptide-conjugated PEG liposomes targeting the integrin $\alpha 2 \beta 1$ receptor. International Journal of Pharmaceutics 2012, 428 (1), 171-177. DOI: https://doi.org/10.1016/j.ijpharm.2012.02.043.

59. Garg, A.; Tisdale, A. W.; Haidari, E.; Kokkoli, E., Targeting colon cancer cells using PEGylated liposomes modified with a fibronectin-mimetic peptide. International journal of pharmaceutics 2009, 366 (1-2), 201-10. DOI: 10.1016/j.ijpharm.2008.09.016.

60. Lasch, J.; Weissig, V.; Brandl, M., Preparation of liposomes. In Liposomes-A Practical Approach., $2^{\text {nd }}$ ed.; Torchilin, V. P.; Weissig, V., Eds. Oxford University Press: 2003; pp 3 - 30 . .

61. Stewart, J. C. M., Colorimetric determination of phospholipids with ammonium ferrothiocyanate. Analytical Biochemistry 1980, 104 (1), 10-14. DOI: https://doi.org/10.1016/0003-2697(80)90269-9.

62. Smith, P. K.; Krohn, R. I.; Hermanson, G. T.; Mallia, A. K.; Gartner, F. H.; Provenzano, M. D.; Fujimoto, E. K.; Goeke, N. M.; Olson, B. J.; Klenk, D. C., Measurement of protein using bicinchoninic acid. Analytical biochemistry 1985, 150 (1), 76-85.

63. Jimah, J. R.; Schlesinger, P. H.; Tolia, N. H., Liposome Disruption Assay to Examine Lytic Properties of Biomolecules. Bio Protoc 2017, 7 (15). DOI: 10.21769/BioProtoc.2433.

64. Chien-Chung, J.; Cheng, S.-H.; Ho, J.-a. A.; Hong-Yi Huang, S.; C. Chang, J.; Pi-Ju, T.; Chung-Shi, Y.; Lo, L.-W., Dynamic Probing of Nanoparticle Stability In Vivo: A Liposomal Model Assessed Using In Situ Microdialysis and Optical Imaging. 2011; Vol. 2011. DOI: 10.1155/2011/932719.

65. Simões, S.; Slepushkin, V.; Düzgünes, N.; Pedroso de Lima, M. C., On the mechanisms of internalization and intracellular delivery mediated by $\mathrm{pH}$-sensitive liposomes. Biochimica et Biophysica Acta (BBA) - Biomembranes 2001, 1515 (1), 23-37. DOI: https://doi.org/10.1016/S0005-2736(01)00389-3. 66. Immobilized-Liposome Sensor System for Detection of Proteins under Stress Conditions. MEMBRANE 2007, 32 (5), 294-301. DOI: 10.5360/membrane.32.

67. Nagasaka, Y., Simple and Convenient Method for Estimation of Marker Entrapped in Liposomes AU - Ishii, Fumiyoshi. Journal of Dispersion Science and Technology 2001, 22 (1), 97-101. DOI: 10.1081/DIS100102684. 
68. Abuchowski, A.; van Es, T.; Palczuk, N. C.; Davis, F. F., Alteration of immunological properties of bovine serum albumin by covalent attachment of polyethylene glycol. The Journal of biological chemistry 1977, 252 (11), 3578-81.

69. Pollock, S.; Antrobus, R.; Newton, L.; Kampa, B.; Rossa, J.; Latham, S.; Nichita, N. B.; Dwek, R. A.; Zitzmann, N., Uptake and trafficking of liposomes to the endoplasmic reticulum. Faseb j 2010, 24 (6), 186678. DOI: 10.1096/fj.09-145755.

70. Hoekman, J. D.; Srivastava, P.; Ho, R. J., Aerosol-stable peptide-coated liposome nanoparticles: a proof-of-concept study with opioid fentanyl in enhancing analgesic effects and reducing plasma drug exposure. J Pharm Sci 2014, 103 (8), 2231-9. DOI: 10.1002/jps.24022.

71. Leighton, T. G., 2 - Cavitation Inception and Fluid Dynamics. In The Acoustic Bubble, Leighton, T. G., Ed. Academic Press: 1994; pp 67-128. DOI: https://doi.org/10.1016/B978-0-12-441920-9.50007-9.

72. Moussa, H. G.; Martins, A. M.; Husseini, G. A., Review on triggered liposomal drug delivery with a focus on ultrasound. Curr Cancer Drug Targets 2015, 15 (4), 282-313.

73. Kinoshita, M.; Hynynen, K., A novel method for the intracellular delivery of siRNA using microbubble-enhanced focused ultrasound. Biochemical and biophysical research communications 2005, 335 (2), 393-9. DOI: 10.1016/j.bbrc.2005.07.101.

74. Aryal, M.; Vykhodtseva, N.; Zhang, Y. Z.; Park, J.; McDannold, N., Multiple treatments with liposomal doxorubicin and ultrasound-induced disruption of blood-tumor and blood-brain barriers improve outcomes in a rat glioma model. Journal of controlled release : official journal of the Controlled Release Society 2013, 169 (1-2), 103-11. DOI: 10.1016/j.jconrel.2013.04.007.

75. M. Maynard, V.; Magin, R.; R. Strom-Jensen, P.; Dunn, F., Ultrasonic Absorption by Liposomes. 1983; Vol. 2. DOI: 10.1109/ultsym.1983.198171.

76. Tata, D. B.; Dunn, F., Interaction of ultrasound and model membrane systems: analyses and predictions. The Journal of Physical Chemistry 1992, 96 (8), 3548-3555. DOI: 10.1021/j100187a067.

77. Lin, H.-Y.; Thomas, J. L., PEG-Lipids and Oligo(ethylene glycol) Surfactants Enhance the Ultrasonic Permeabilizability of Liposomes. Langmuir 2003, 19 (4), 1098-1105. DOI: 10.1021/la026604t.

78. Hagtvet, E.; Evjen, T. J.; Olsen, D. R.; Fossheim, S. L.; Nilssen, E. A., Ultrasound enhanced antitumor activity of liposomal doxorubicin in mice. Journal of drug targeting 2011, 19 (8), 701-8. DOI: 10.3109/1061186x.2010.551401.

79. Finer, E. G.; Flook, A. G.; Hauser, H., Mechanism of sonication of aqueous egg yolk lecithin dispersions and nature of the resultant particles. Biochimica et biophysica acta 1972, 260 (1), 49-58.

80. Lasic, D. D., The mechanism of vesicle formation. Biochemical Journal 1988, 256 (1), 1-11.

81. Lawaczeck, R.; Kainosho, M.; Chan, S. I., The formation and annealing of structural defects in lipid bilayer vesicles. Biochimica et biophysica acta 1976, 443 (3), 313-30.

82. Mendelsohn, R.; Sunder, S.; Bernstein, H. J., The effect of sonication on the hydrocarbon chain conformation in model membrane systems: A Raman spectroscopic study. Biochimica et Biophysica Acta (BBA) - Biomembranes 1976, 419 (3), 563-569. DOI: https://doi.org/10.1016/0005-2736(76)90270-4.

83. Borden, M. A.; Kruse, D. E.; Caskey, C. F.; Zhao, S.; Dayton, P. A.; Ferrara, K. W., Influence of lipid shell physicochemical properties on ultrasound-induced microbubble destruction. IEEE transactions on ultrasonics, ferroelectrics, and frequency control 2005, 52 (11), 1992-2002.

84. Hauser, H.; Barratt, M. D., Effect of chain length on the stability of lecithin bilayers. Biochemical and biophysical research communications 1973, 53 (2), 399-405. DOI: https://doi.org/10.1016/0006291X(73)90675-X.

85. Lin, H. Y.; Thomas, J. L., Factors affecting responsivity of unilamellar liposomes to $20 \mathrm{kHz}$ ultrasound. Langmuir 2004, 20 (15), 6100-6. DOI: 10.1021/la049866z.

86. Garbuzenko, O.; Barenholz, Y.; Priev, A., Effect of grafted PEG on liposome size and on compressibility and packing of lipid bilayer. Chemistry and physics of lipids 2005, 135 (2), 117-29. DOI: 10.1016/j.chemphyslip.2005.02.003. 
87. Priev, A.; Zalipsky, S.; Cohen, R.; Barenholz, Y., Determination of Critical Micelle Concentration of Lipopolymers and Other Amphiphiles: Comparison of Sound Velocity and Fluorescent Measurements. Langmuir 2002, 18 (3), 612-617. DOI: 10.1021/la0110085.

88. Ickenstein, L. M.; Arfvidsson, M. C.; Needham, D.; Mayer, L. D.; Edwards, K., Disc formation in cholesterol-free liposomes during phase transition. Biochimica et Biophysica Acta (BBA) - Biomembranes 2003, 1614 (2), 135-138. DOI: https://doi.org/10.1016/S0005-2736(03)00196-2.

89. Leal, C.; Rögnvaldsson, S.; Fossheim, S.; Nilssen, E. A.; Topgaard, D., Dynamic and structural aspects of PEGylated liposomes monitored by NMR. Journal of Colloid and Interface Science 2008, 325 (2), 485-493. DOI: https://doi.org/10.1016/j.jcis.2008.05.051. 


\section{For Table of Contents Use Only}

The acoustic release of three targeted liposomes (Human serum albumin, Transferrin and RGD) subjected to low-frequency ultrasound

Nahid S. Awad, Vinod Paul, Mohamad S. Mahmoud, Nour M. AlSawaftah, Paul S. Kawak, Mohammad H. Al Sayah, Ghaleb A. Husseini

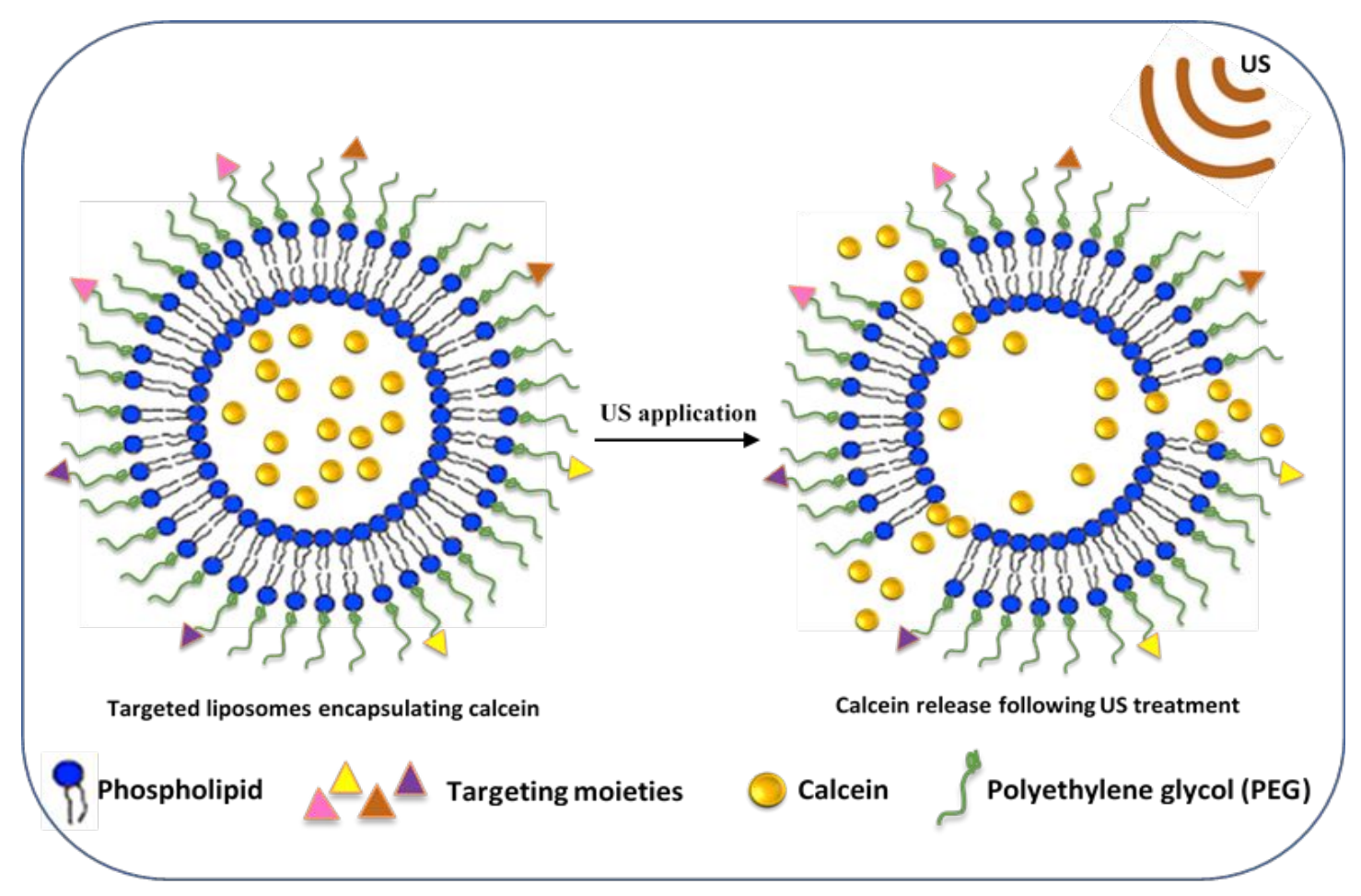




\section{Supplemental data}



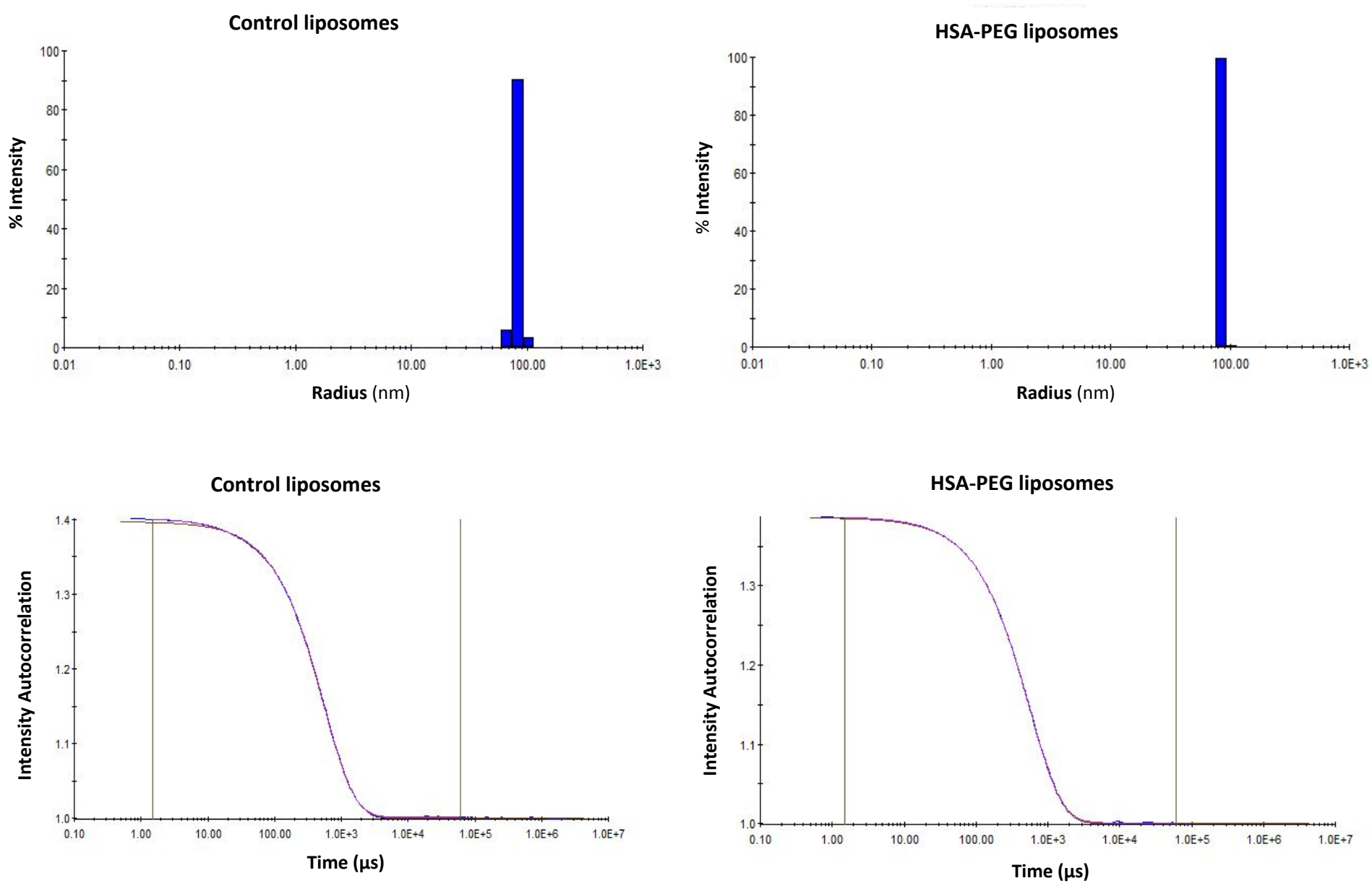

Figure 1. DLS output showing both the size distribution and correlation curve of control and HSA-PEG liposomes 

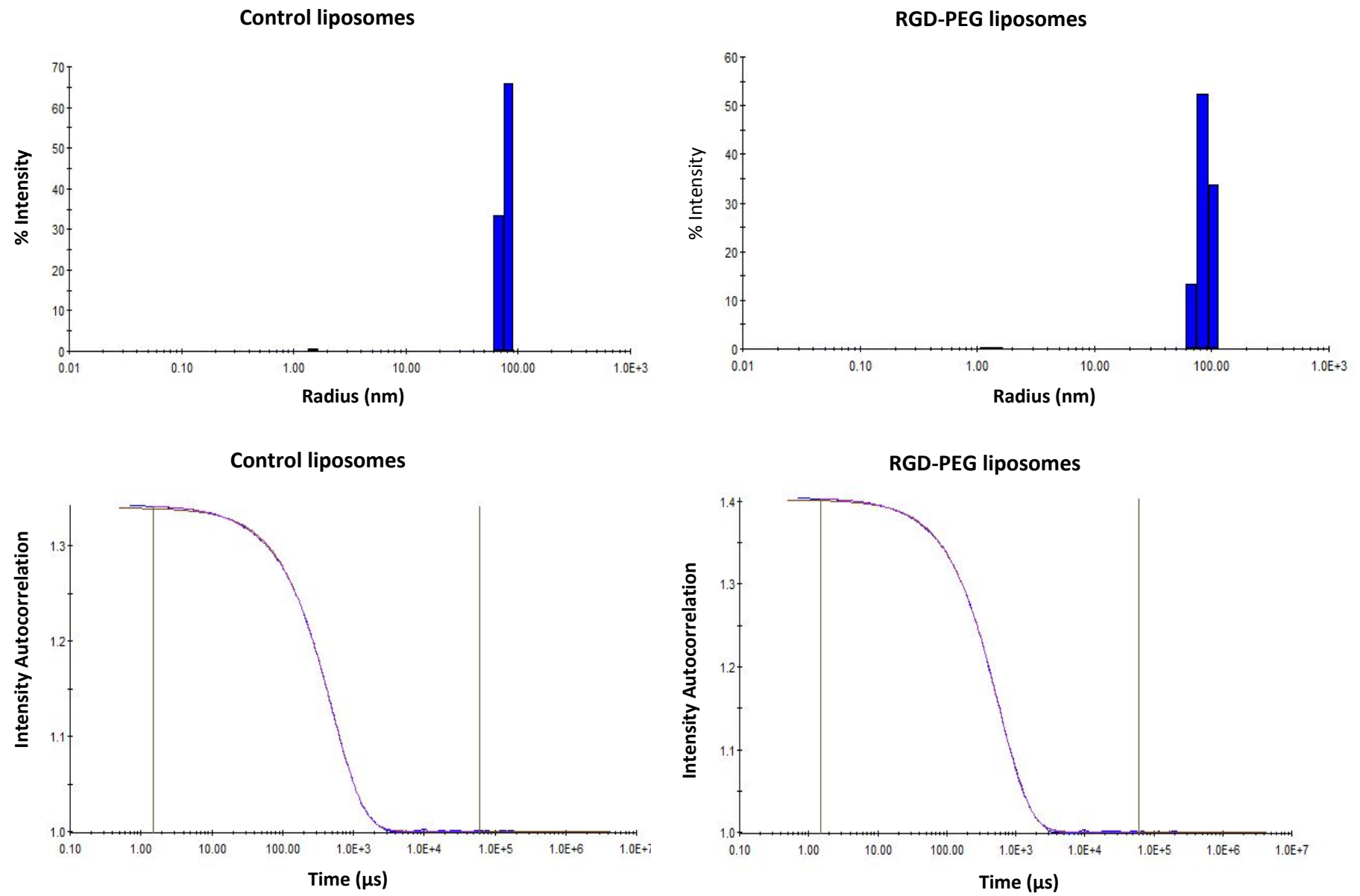

Figure 2. DLS output showing both the size distribution and correlation curve of control and RGD-PEG liposomes 

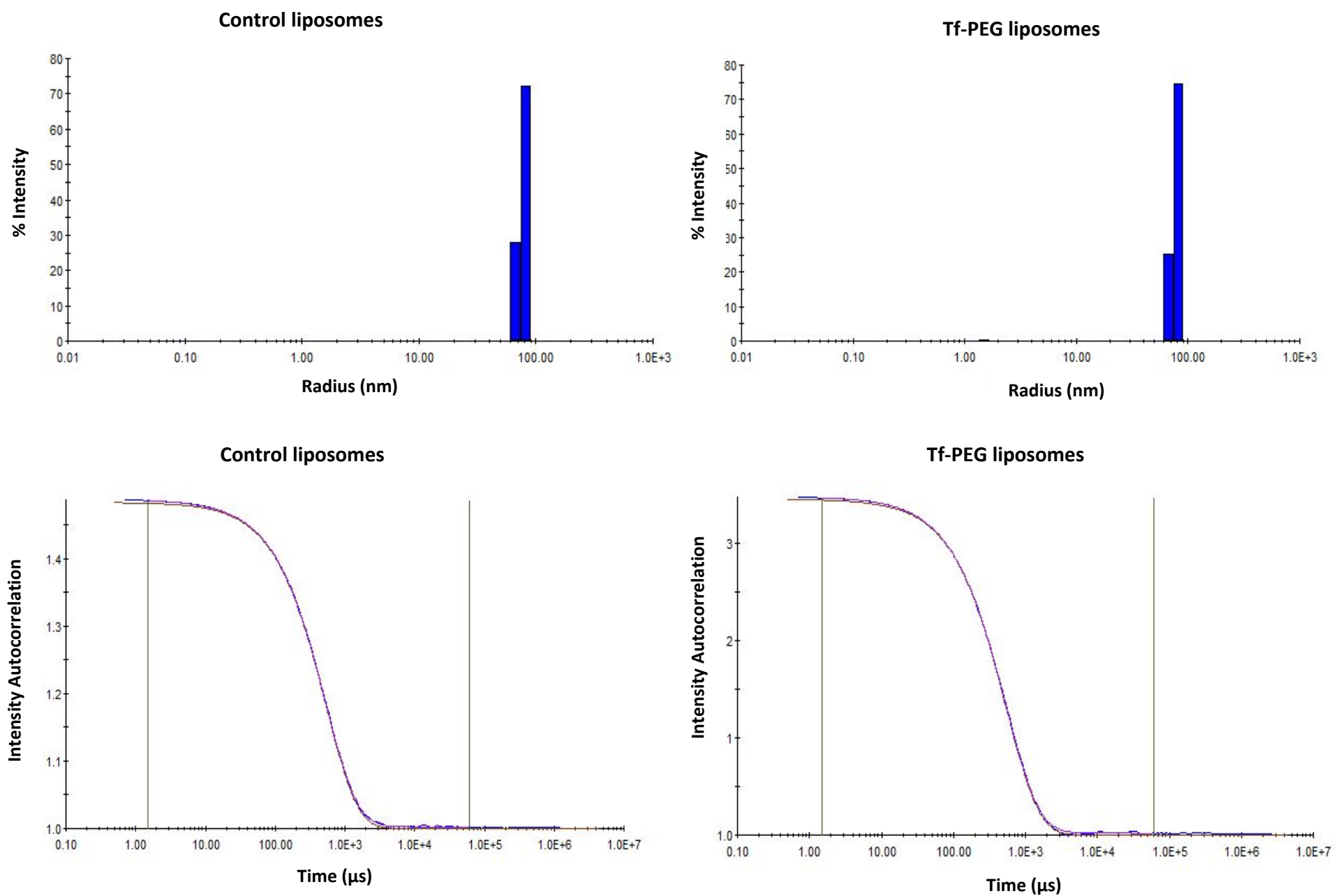

Figure 3. DLS output showing both the size distribution and correlation curve of control and Tf-PEG liposomes 